\title{
Participação social no diagnóstico e prognóstico do Plano de Recursos Hídricos da Região Hidrográfica do Paraguai
}

Analysis of social participation in the National Water Resources Plan for the Upper Paraguay

Basin

Participación social en el diagnóstico y pronóstico del Plan de Recursos Hídricos de la Región

Hidrográfica de Paraguay

Recebido: 12/07/2021 | Revisado: 16/07/2021 | Aceito: 15/08/2021 | Publicado: 17/08/2021

\author{
MaiaraThaisa Oliveira Rabelo \\ ORCID: https://orcid.org/0000-0003-1526-5047 \\ Universidade do Estado de Mato Grosso, Brasil \\ E-mail: tha.rabelo@hotmail.com \\ Daniela Maimoni de Figueiredo \\ ORCID: https://orcid.org/0000-0002-2229-0905 \\ Universidade Federal do Estado de Mato Grosso, Brasil \\ E-mail: dani_figueiredo@uol.com.br \\ Joari Costa de Arruda \\ ORCID: https://orcid.org/0000-0001-8813-983X \\ Universidade do Estado de Mato Grosso, Brasil \\ E-mail: arrudajcbio@gmail.com \\ Carolina Joana da Silva \\ ORCID: https://orcid.org/0000-0003-0517-1661 \\ Universidade do Estado de Mato Grosso, Brasil \\ E-mail: ecopanta@terra.com.br
}

\begin{abstract}
Resumo
A elaboração do Plano de Recursos Hídricos caracteriza-se em um processo de estudo, diálogo e consenso contínuo, fornecendo um contexto da situação real dos Recursos Hídricos em diferentes realidades e cenários. Neste sentido o objetivo deste trabalho foi analisar o processo de participação social na elaboração do Plano de Recursos Hídricos da Região Hidrográfica do Alto rio Paraguai, entre os estados de MT e MS. Foram realizadas oficinas onde os participantes eram agrupados em categorias de stakeholders, para discutir os desafios e as potencialidades identificados na bacia. Os resultados demostraram que os temas mais recorrentes estavam relacionados com: saneamento básico, excesso de pequenas centrais hidrelétricas ( $\mathrm{PCH} S$ ), uso indiscriminado de agrotóxicos, pesca predatória, queimadas, proteção dos recursos naturais, recuperação e conservação das nascentes, implementação de modelo de turismo ecológico e conservação da biodiversidade. Embora o estudo tenha identificado diferenças na representação dos grupos sociais, todos demonstraram interesse na elaboração do Plano de Recursos Hídricos da Região Hidrográfica do Alto Paraguai.
\end{abstract}

Palavras-chave: Governança; Educação Ambiental; Política Pública.

\begin{abstract}
The elaboration of the Water Resources Plan is characterized by a process of study, dialogue and continuous consensus, providing a picture of the real situation of Water Resources in different realities and scenarios. In this sense, the objective of this work was to describe the process of social participation in the elaboration of the Water Resources Plan for the Upper Paraguay Basin. Workshops were held where participants were grouped into categories of stakeholders to discuss the challenges and potential applied in the basin. The results demonstrated on the most recurrent themes are related to: basic sanitation, excess of $\mathrm{PCH}$, indiscriminate use of pesticides, overfishing, burning, protection of natural resources, recovery and conservation of springs, ecological tourism model and biodiversity conservation. Although the study identified differences in the representation of social groups, all showed interest in the elaboration of the Water Resources Plan for the Hydrographic Region of Alto Paraguay.
\end{abstract}

Keywords: Governance; Environmental Education; Public Policy.

\section{Resumen}

La elaboración del Plan de Recursos Hídricos se caracteriza en un proceso de estudio, diálogo y consenso continuo, brindando un contexto de la situación real de los Recursos Hídricos en diferentes realidades y escenarios. En este sentido, el objetivo de este trabajo fue analizar el proceso de participación social en la elaboración del Plan de Recursos Hídricos de la Región Hidrográfica del Alto Río Paraguay, entre los estados de MT y MS. Se llevaron a 
cabo talleres donde los participantes se agruparon en categorías de partes interesadas para discutir los desafíos y el potencial identificado en la cuenca. Los resultados mostraron que los temas más recurrentes estuvieron relacionados con: saneamiento básico, exceso de pequeñas centrales hidroeléctricas (PCH'S), uso indiscriminado de plaguicidas, pesca depredadora, quema, protección de recursos naturales, recuperación y conservación de manantiales, implementación de un modelo turístico. conservación ecológica y de la biodiversidad. Si bien el estudio identificó diferencias en la representación de los grupos sociales, todos mostraron interés en elaborar el Plan de Recursos Hídricos de la Región Alto del Río Paraguay.

Palabras clave: Gobernanza; Educación ambiental; Política pública.

\section{Introdução}

O Brasil possui doze regiões hidrográficas, que correspondem à cerca de $12 \%$ de toda água doce disponível no planeta (Brasil, 2017). Dentre estas encontrasse a Região Hidrográfica do Rio Paraguai (RH-Paraguai), formadora da planície do Pantanal, uma das maiores áreas úmidas do planeta. As áreas úmidas fornecem uma miríade de serviços ao ser humano, locais com um dos maiores estoques de carbono do planeta, atuam na redução de poluentes e são uma das últimas grandes áreas mantidas como uso comum pela comunidade (Pearce e Madgwick, 2020). São conceituadas como ecossistemas na interface entre ambientes terrestres e aquáticos, permanentemente ou periodicamente inundados, solos encharcados, com comunidades de plantas e animais adaptadas à sua dinâmica hídrica (Da Cunha et al. 2014). São ecossistemas mais afetados e ameaçados de destruição pelo homem (Pearce e Madgwick, 2020).

O Pantanal é uma área úmida periodicamente inundada, implicando em dois períodos hidrológicos distintos ao longo do ano, cheia e estiagem. A hidrologia é complexa e influenciada pela descarga de vários rios que proveem das partes mais altas e transbordam na planície, além da água proveniente da precipitação, imprescindível em algumas áreas de menor inundação (Da Silva e Esteves,1995; Junk et al. 2011). A conexão dos rios com a planície, juntamente com a sazonalidade de chuvas, resulta na variação anual do nível da água (pulso de inundação), fundamental para garantir os processos ecológicos do sistema, a diversidade biológica, de habitats e de paisagens, o que torna o Pantanal um bioma único. O pulso de inundação, principal fenômeno ecológico que regula o regime anual de cheia e seca do Pantanal, determina a existência, a produtividade e a interação entre as espécies, aquáticas e terrestres, coabitantes do bioma pantaneiro, além das atividades econômicas da região (Wantzen et al. 2008). Este bioma se conecta com Cerrado por meio da área de planalto que o circunda, onde proveem os rios que conduzem água, sedimentos e nutrientes para a planície.

Diversas pesquisas têm investigado os impactos socioambientais na RH-Paraguai, principalmente os que resultam no desequilíbrio do pulso de inundação, sendo que a maior parte dos impactos têm origem em atividades que ocorrem no Planalto que circunda o Pantanal. Dentre as atividades, destacam-se o agro ecossistemas para a produção de commodities (Da Silva et al. 2001; Da Silva e Girard, 2004; Da Silva, 2015), a construção de usinas e pequenas centrais hidrelétricas (Rossi et al. 2018) e o uso da água para a diluição de esgoto doméstico das cidades (Rondon Lima et al. 2018).

Da Silva et al. (2015) realizaram um estudo por meio da análise DPSIR (drives, pressurs, state, impacts, responses), cujos resultados apontaram as políticas públicas, ligadas ao desenvolvimento do setor agrícola e energético, como as principais forças motrizes (drivers) que causam a fragmentação dos ecossistemas e da conectividade hidrológica dos rios desta bacia e são as principais causas dos conflitos e impactos socioambientais na RH-Paraguai.

Por outro lado, as políticas públicas da área ambiental têm como principais desafios minimizar esses impactos, bem como regulamentar, fiscalizar e ordenar as atividades econômicas. Dentre estas políticas, destaca-se a Política Nacional de Recursos Hídricos - PNRH (Brasil, 1997), que tem como objetivos a utilização racional da água e a gestão integrada com os usos do solo no âmbito das bacias hidrográficas. A lei destaca quanto aos usos múltiplos da água, abrangendo, de forma igualitária, todos os usuários e a busca pela gestão integrada dos recursos hídricos com outras políticas setoriais (agricultura, turismo, saneamento, energia, indústria, entre outros). Foram estabelecidos por lei cinco instrumentos de gestão, quais sejam: 
enquadramento dos corpos d'água superficiais, outorga de uso da água, cobrança, sistema de informações e plano de recursos hídricos.

Cada Estado brasileiro tem sua própria política de recursos hídricos, que também estabelece, em sua maioria, esses mesmos instrumentos de gestão, a exemplo de Mato Grosso (Lei Estadual 6.495/1997, substituída pela Lei Estadual 11.088 de 2020) e Mato Grosso do Sul (Lei Estadual 2.406/2002), estados que possuem parte de seu território na RH-Paraguai, onde estes instrumentos foram, até o presente momento, parcialmente regulamentados e implementados (Moretti e Marinho, 2016; Marchetto et al. 2018;).

Dentre os cinco instrumentos, o Plano de Recursos Hídricos é o mais amplo e completo, uma vez que tem como objetivo central orientar a gestão das águas, estabelecendo um pacto capaz de definir diretrizes e políticas públicas que aperfeiçoem a oferta de água (Bolson e Haonat, 2016). Na Lei Federal 9.433 (Brasil, 1997), o Plano de Recursos Hídricos, seja este da esfera nacional, estadual ou das bacias hidrográficas, são planos diretores que visam a fundamentar e orientar a implementação da PNRH e o gerenciamento dos recursos hídricos, sendo planos de longo prazo, com horizonte de planejamento compatível com o período de implantação de seus programas e projetos.

Para Milani (2008) a elaboração desse plano caracteriza-se em um processo de estudo, diálogo e consenso contínuos, fornecendo um retrato da situação real dos recursos hídricos em diferentes realidades e cenários, atra vés da participação social ativa. A participação social ativa é considerada como uma mudança da gestão simples, centrada no governo, para uma gestão complexa das águas, onde a participação cidadã é ampliada na tomada das decisões públicas por uma ética de corresponsabilidade entre governo e sociedade, o que inclui os saberes populares oriundos das vivências locais (LópezRamírez, 2016).

Além dos instrumentos de gestão, a PNRH criou arranjos institucionais que incluem espaços participativos de discussão e gestão da água, ou seja, pressupõe uma governança participativa. No âmbito da bacia hidrográfica esta função fica a cargo dos comitês de bacia hidrográfica (CBHs), enquanto que nas esferas estadual e da união, são os Conselhos de Recursos Hídricos que cumprem este papel. Bruno e Fantin-Cruz (2020) identificaram algumas limitações à atuação dos CBHs em Mato Grosso, dentre estas a ausência de Planos de Bacias das áreas de atuação destes colegiados.

Em 2013, o Conselho Nacional de Recursos Hídricos aprovou a elaboração do Plano de Recursos Hídricos da RHParaguai (Brasil, 2013), resultante da união de esforços da sociedade civil, da comunidade científica e dos movimentos socioambientais. O Plano de Recursos Hídricos da Região Hidrográfica do Paraguai (PRH Paraguai) foi elaborado durante três anos, a partir de dezembro de 2016, pela Agência Nacional de Águas (ANA), com o propósito de:

“... reunir dados atualizados sobre a Região Hidrográfica do Rio Paraguai, interpretá-los e mapeá-los; definir cenários futuros; identificar áreas críticas e propor diretrizes para os instrumentos de gestão; estabelecer objetivos e metas; definir ações de curto, médio e longo prazos e os custos envolvidos, constituindo assim um instrumento de planejamento estratégico de longo prazo, para uma adequada gestão dos recursos hídricos desta região hidrográfica" (ANA, 2017).

O processo de construção deste ocorreu por meio de oficinas públicas com a participação de vários grupos sociais dos Estados de Mato Grosso e Mato Grosso do Sul. A análise da dinâmica e dos resultados destas oficinas, bem como a identificação dos diferentes grupos sociais e dos conflitos políticos-socioambientais que emergiram nestas oficinas, são objetos do presente estudo, cuja abordagem representa uma contribuição para o debate das práticas de governança da água na construção de um instrumento de gestão, ainda pouco explorados na literatura científica. 


\section{Metodologia}

\section{1 Área de estudo}

A RH-Paraguai, uma das doze regiões hidrográficas brasileiras, ocupa uma área total de cerca de $1.135 .000 \mathrm{~km}^{2} \mathrm{e}$ abrange os estados do Mato Grosso, Mato Grosso do Sul e três países vizinhos, Argentina, Paraguai e Bolívia. No contexto da política das águas, a RH-Paraguai tem como principal curso d'água o rio Paraguai, cuja nascente se localiza na Chapada dos Parecis, no estado de Mato Grosso. Esta região hidrográfica pode ser dividida em três áreas geomorfologicamente distintas: a região de Planalto, que abrange terras acima de $200 \mathrm{~m}$ de altitude, as depressões, regiões de nível mais baixo do que o Planalto com atitudes entre $100 \mathrm{~m}$ e 500m, e a planície do Pantanal, de terras de menos de 200m de altitude (Almeida, 1945), sendo a maior área úmida do mundo, Patrimônio Nacional, Reserva da Bioesfera (UNESCO) e com sítios reconhecidos pela Convenção RAMSAR.

Em relação à abrangência regional em território brasileiro, a Bacia compreende a área de 86 Municípios, dos quais 53 pertencem ao Mato Grosso e 33 ao Mato Grosso do Sul . A população total da Região Hidrográfica, de acordo com os dados das bases do PNRH 2005, totalizava, em 2000, 1.887 .365 habitantes, dos quais 1.597 .601 (84,15\%) correspondem à área urbana e 289.067 (15,32\%) à área rural (Conjuntura, 2013).

As principais cidades em Mato Grosso, localizadas na Região Hidrográfica, que promovem a economia da região são: Cuiabá, com 483.346 habitantes; Várzea Grande, com 215.298 habitantes, região metropolitana da Grande Cuiabá, que possui economia concentrada no comércio e indústria. Além disso, ambas as cidades estão separadas apenas pelas margens do rio Cuiabá, importante tributário para a RH-Paraguai. Seguido por Rondonópolis, com 150.227 habitantes, a indústria e o agronegócio são as principais fontes econômicas. Cáceres, com 85.857 habitantes, tem na agropecuária sua principal fonte de renda. O turismo, especialmente de pesca esportiva, vem se destacando, por ostentar grandes potencialidades turísticas com o rio Paraguai e Jauru (Conjuntura, 2013).

No Mato Grosso do Sul, cidades que exercem importante função econômica dentro da região hidrográfica e eleitas para a realização das oficinas: Corumbá, com 95.901 habitantes, no Pantanal; Coxim, com 31.797 habitantes, (as águas piscosas dos rios Taquari, Coxim, Jauru e Piquiri atraem turistas de pesca amadora de todo país) e Bonito, com 19.587 habitantes e que também exerce grande importância no setor econômico da região advinda do ecoturismo nos principais rios, tributário importantes, como o rio Formoso, rio da Prata, rio Mimoso e Miranda (Conjuntura, 2013).

A RH-Paraguai está incorporada à macroeconomia global desde as décadas de 1960/70, quando foi impulsionada por diversos planos e programas governamentais de ocupação, integração e desenvolvimento regional, destinados em especial à agricultura de exportação e à pecuária de corte no centro-oeste (SEPLAN/MT, 2002). Na década de 1980, houve também um ciclo de exploração do ouro (Mendes, 1992). Os fluxos migratórios decorrentes do desenvolvimento destas atividades econômicas impulsionaram o surgimento e o progresso de cidades. Recentemente, programas setoriais conservacionistas surgem através do incentivo a novas atividades, como por exemplo o ecoturismo e à pesca artesanal e aquicultura (Brasil, 2008).

\subsection{Coleta e análise dos dados}

A primeira fase desta pesquisa tratou da identificação e caracterização dos grupos sociais presentes nas seis oficinas que foram realizadas para a elaboração do Plano de recursos hídricos da RH-Paraguai, que ocorreram em Mato Grosso (MT) e Mato Grosso do Sul (MS). Para tanto, foram utilizadas as listas de presença e a observação participante dos grupos sociais nas reuniões, segundo a classificação utilizada pela ANA - Agência Nacional da Água: a) sociedade civil - composto pelas Universidades (alunos e professores), membro de Organizações Não Governamentais (ONG’s), pescadores, comunidades tradicionais, moradores locais, interessados em geral; b) Usuários da água bruta - composto por representantes de associações 
comerciais, empresas de saneamento básico, mercado e c) Poder público - composto por membros das secretarias de meio ambiente, prefeituras, e de outras instituições públicas como ICMBio, IBAMA, CONDEMA entre outros. Por se tratar de uma pesquisa qualitativa utilizamos como suporte metodológico as recomendações de (Estrela, 2018; Ludke. e Andre, 2013).

As seis oficinas foram realizadas no período de 31/07/2017 a 01/09/2017 nas cidades de Corumbá, Coxim e Bonito no Mato Grosso do Sul e Cáceres, Cuiabá e Rondonópolis no estado de Mato Grosso, sendo que nestas três últimas cidades também foi feita a observação participante nas reuniões, método etnográfico no qual o observador participa ativamente das atividades desenvolvidas pelos grupos sociais, recolhendo dados de acordo com os critérios apontados por (Pawlowski, et al. 2016).

Os resultados dessa fase da pesquisa referem-se à primeira etapa de elaboração do plano - a fase de diagnóstico e prognóstico. As reuniões desta fase foram realizadas por meio das dinâmicas propostas pela ANA e a ENGECORPS Engenharia S.A., responsáveis pela elaboração do plano. Para a realização do diagnóstico, os organizadores utilizaram a metodologia da Agenda 21 do Pedaço (Instituto ECOAR, 1997) que, através de uma técnica participativa, objetiva sensibilizar e envolver a população em processos de tomada de decisões e solução de problemas, abrindo espaço para o debate de adversidades e ações conjuntas. Os participantes apontam as questões que as afligem dentro do tema proposto, construindo seu Muro das Lamentações e a situação ideal desejada ao plantarem sua Árvore dos Sonhos (Araújo et al. 2015).

Na primeira dinâmica, Muro das Lamentações, foi pedido aos presentes que escrevessem em papel, cortado com formato de tijolo, o que não funciona corretamente em sua região e o que precisa melhorar no que diz respeito ao meio ambiente. Ao ser realizada a atividade, os participantes colaram as suas lamentações na parede, construindo assim o muro.

Na segunda dinâmica, Árvore dos Sonhos, os participantes escreveram, em papeis cortados em forma de folhas, suas opiniões de como deverá ser o futuro ambiental da região. Na sequência, foi estruturada a Árvore dos Sonhos com as respostas de todos os integrantes escritas nas folhas.

A segunda etapa desta pesquisa tratou, portanto, da organização dos dados dessas duas dinâmicas, por meio da transcrição de todas as informações expostas nas oficinas nos seis municípios de Mato Grosso e Mato Grosso do Sul.

Frases e palavras com o mesmo significado foram agrupadas, como no caso de saneamento, que integrou o conjunto de serviços e infraestrutura em tratamento e coleta de esgoto, abastecimento público, coleta e destinação de resíduos sólidos e drenagem urbana.

Para tratar os dados coletados nas dinâmicas foi utilizado o Voyant Tool (Sinclair e Rockwell, 2012) que é um aplicativo de código aberto e gratuito que permite trabalhar com os seus próprios textos ou coleções de texto existentes para executar funções básicas de mineração de palavras (http://voyant-tools.org/). Estas funções permitem extrair rapidamente características comuns entre os dois Estados e identificar quais foram às palavras mais ditas em cada um.

A transcrição integral do conteúdo de todas as dinâmicas foi inserida no programa, buscando destacar as palavras mais utilizadas e os temas comuns mais enfatizados. Na sequência, foram inseridos os temas filtrados por cidade, a frequência de citação das palavras, as quais foram utilizadas como interesses e preocupações. As 20 palavras mais citadas nas reuniões dos dois Estados foram comparadas com as 20 mais citadas em cada cidade onde ocorreram estas oficinas.

Nesta comparação, surgiram 10 palavras presentes em todas as listas, gerando um ranking com os termos mais citados por todos os grupos e comparados quanto à frequência de citações individuais em cada cidade. As similaridades ou dissimilaridades foram identificadas e comparadas para apontar os conflitos e cooperações entre os atores sociais ativos na bacia.

Para a análise de respostas agrupadas, as similaridades destas foram avaliadas utilizando coeficiente de Jaccard (Real e Vargas, 1996) e pelo método de agrupamento UPGMA (Sneath e Sokal, 1973). O coeficiente de correlação, que indica a correspondência entre a matriz de similaridade de pares de elementos com a representação gráfica (máscara da árvore) foi 
calculado pelo o programa PAST versão 1.79 (Hammer et al. 2001).

\section{Resultados}

\subsection{Participação dos atores sociais}

As seis oficinas avaliadas neste estudo contaram com a participação de 249 pessoas, categorizadas nos seguimentos: sociedade civil, usuários da água bruta e poder público.

No estado de Mato Grosso (MT), a sociedade civil apresentou maior participação em número de pessoas presentes em todas as cidades, seguido pelo poder público e usuários. Em Cáceres, estiveram presentes 30 representantes da Sociedade Civil, 8 membros representando os Usuários da Água Bruta e 20 pessoas pertencentes ao grupo social Poder Público, totalizando 58 participantes. Em Cuiabá, a capital do Estado, houveram 30 pessoas da Sociedade Civil, 18 integrantes do grupo de Usuários da Água e 16 do Poder Público, totalizando 64 pessoas presentes. Já em Rondonópolis, estiveram presentes 17 pessoas que compunham a Sociedade Civil, 3 do grupo de Usuários da Água e 16 representantes do Poder Público o que totalizou 30 presentes.

De maneira geral, em Mato Grosso do Sul, Bonito recebeu 4 membros da Sociedade Civil, 3 Usuários da Água e 12 representantes do Poder Público totalizando 19 pessoas presentes e Corumbá contou com a presença de 5 pessoas da Sociedade Civil, 4 representantes do grupo social Usuários da Água e 13 pessoas do Poder Público, totalizando assim, 22 pessoas presentes. Porém, em Coxim, a maioria dos participantes compunham a sociedade civil, com 39 pessoas presentes, seguido por usuários com 8 pessoas e poder público com 6 representantes presentes, o que totalizou 53 pessoas na oficina. (Figura 1).

Figura 1 - Participação por grupo social nas oficinas para a construção do Plano de Recursos Hídricos da RH-Paraguai em 2017.

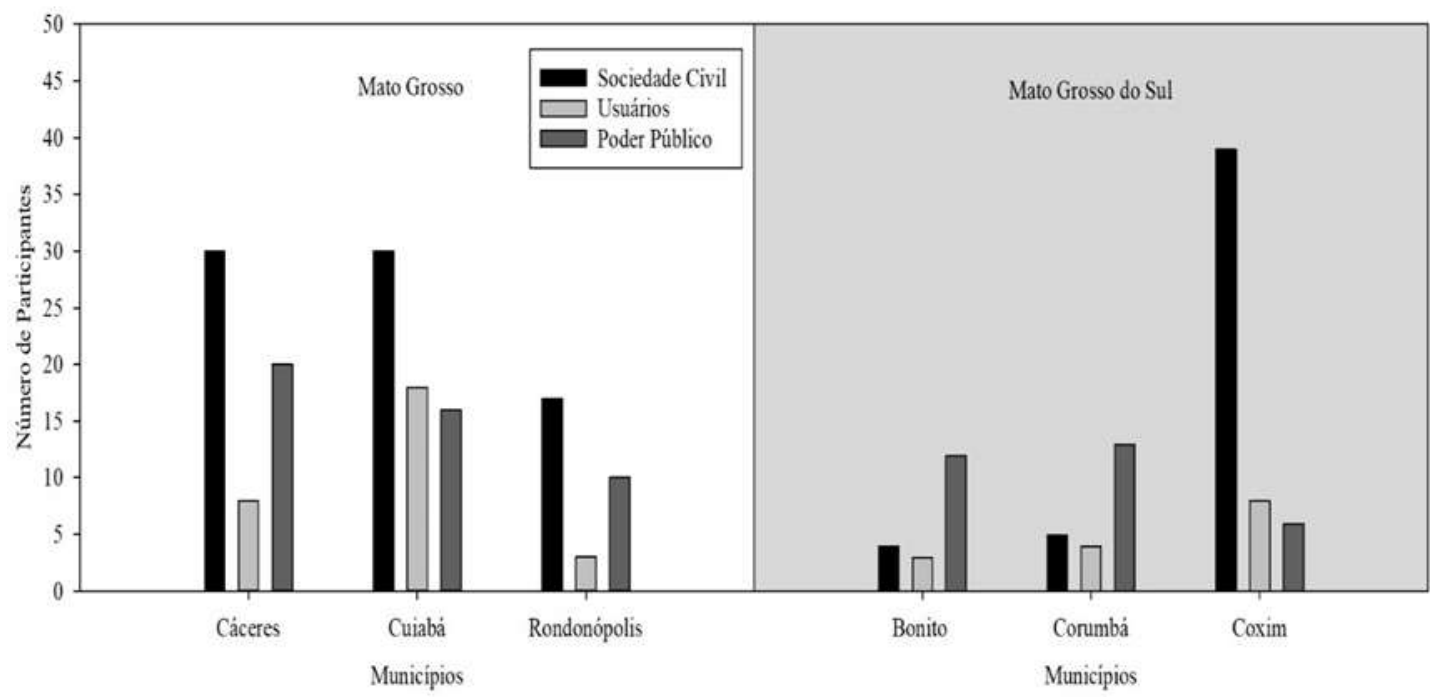

Fonte: Construção dos autores.

Nas seis oficinas houve variação quanto a participação de homens e mulheres, no entanto, as diferenças entre eles não foram expressivas. Em MT os municípios que tiveram maior participação de homens foram Cáceres, com 33 participantes, seguido de Cuiabá e Rondonópolis, com 26 e 16, respectivamente. Quanto à participação das mulheres, na cidade de Cuiabá foram 38, Cáceres 25 e Rondonópolis 14. Para MS, as cidades de Coxim tiveram 27 homens e 30 mulheres, Corumbá 13 homens e 9 mulheres e Bonito 11 homens e 7 mulheres respectivamente. A somatória em número de participação dos dois 
estados totalizou 126 homens e 123 mulheres.

\subsection{Muro das Lamentações}

Na avaliação da dinâmica do Muro das lamentações, realizada nas seis oficinas, foram registrados vinte termos mais citados pelos participantes, expostos na Tabela 1.

Tabela 1- Ranking de termos mais citados pelos grupos sociais que participaram das seis oficinas de elaboração do Plano de Recursos Hídricos da RH-Paraguai.

\begin{tabular}{|c|c|c|}
\hline Ranking & Termos & $\mathbf{N}^{\circ}$ de citações \\
\hline $1^{\circ}$ & Saneamento & 305 \\
\hline $2^{\circ}$ & Excesso de PCH's & 93 \\
\hline $3^{\circ}$ & Abuso de Agrotóxicos & 65 \\
\hline $4^{\circ}$ & Avanço da fronteira agrícola & 63 \\
\hline $5^{\circ}$ & Assoreamento & 63 \\
\hline $6^{\circ}$ & Diminuição dos recursos pesqueiros & 55 \\
\hline $7^{\circ}$ & Pesca predatória & 52 \\
\hline $8^{\circ}$ & Mineração & 47 \\
\hline $9^{\circ}$ & Falta de Fiscalização & 42 \\
\hline $10^{\circ}$ & Irregularidades no uso e ocupação do solo & 42 \\
\hline $11^{\circ}$ & Erosão & 34 \\
\hline $12^{\circ}$ & Queimadas & 32 \\
\hline $13^{\circ}$ & Hidrovia Paraná - Paraguai & 30 \\
\hline $14^{\circ}$ & Falta de proteção/fiscalização de uso de APP & 30 \\
\hline $15^{\circ}$ & Desmatamento & 29 \\
\hline $16^{\circ}$ & Dificuldade de acesso a recursos financeiros do governo & 28 \\
\hline $17^{\circ}$ & Falta de conscientização/sensibilização por parte dos moradores & 20 \\
\hline $18^{\circ}$ & Desvalorização do conhecimento tradicional & 17 \\
\hline $19^{\circ}$ & Mudanças climáticas & 17 \\
\hline $20^{\circ}$ & Captação de água nos rios cênicos para criação de açudes & 08 \\
\hline
\end{tabular}

Fonte: Construção dos autores.

As cinco primeiras colocações desse ranking, que expressam as principais preocupações dos grupos sociais presentes nas oficinas, fazem parte de três temas correlatos entre si, políticas de recursos hídricos, energia e agricultura. 
Entre os vinte termos mais citados, dois merecem destaque: o $18^{\circ}$ - 'Desvalorização do conhecimento tradicional', citado 17 vezes apenas pelos participantes das cidades de Cáceres-MT e Coxim-MS. E o 20 - 'Captação de água nos rios cênicos para criação de açudes', citado 08 vezes apenas pelos moradores de Bonito-MS.

Nessa lista, destacam-se ainda dez termos que foram citados em todas as cidades pelo menos uma vez, elencados por ordem da quantidade de repetições, das mais repetidas para as menos repetidas, como mostra a Tabela 2.

Tabela 2 - Ordem decrescente de citações dos 10 termos mais mencionados no Muro das Lamentações da oficina de elaboração do Plano de Recursos Hídricos da RH-Paraguai.

\begin{tabular}{|c|c|c|c|c|c|c|c|}
\hline $\begin{array}{l}\text { Ordem de } \\
\text { citação }\end{array}$ & $\begin{array}{c}\text { Problemas comuns } \\
\text { a todas as cidades }\end{array}$ & Corumbá & Coxim & Bonito & Cáceres & Cuiabá & Rondonópolis \\
\hline 1 & Saneamento & Saneamento & Saneamento & $\begin{array}{l}\text { Falta de proteção/ } \\
\text { fiscalização A PPs }\end{array}$ & Saneamento & Saneamento & Saneamento \\
\hline 2 & Excesso de PCHs & $\begin{array}{c}\text { Diminuição dos } \\
\text { recursos } \\
\text { pesqueiros }\end{array}$ & Erosão & Saneamento & $\begin{array}{c}\text { Diminuição dos } \\
\text { recursos } \\
\text { pesqueiros }\end{array}$ & $\begin{array}{c}\text { Falta de } \\
\text { proteção/ } \\
\text { fiscalização } \\
\text { APPs }\end{array}$ & A buso de $\mathrm{A}$ grotóxicos \\
\hline 3 & $\begin{array}{c}\text { Abuso de } \\
\text { Agrotóxicos }\end{array}$ & Erosão & Excesso de PCHs & $\begin{array}{l}\text { Irregularidades no } \\
\text { uso e ocupação do } \\
\text { solo }\end{array}$ & $\begin{array}{c}\text { Hidrovia Paraná - } \\
\text { Paraguai }\end{array}$ & $\begin{array}{l}\text { Irregularidades } \\
\text { no uso e } \\
\text { ocup ação do } \\
\text { solo }\end{array}$ & $\begin{array}{c}\text { A vanço da fronteira } \\
\text { agricola }\end{array}$ \\
\hline 4 & $\begin{array}{c}\text { Avanço da } \\
\text { fronteira agrícola }\end{array}$ & $\begin{array}{l}\text { Hidrovia } \\
\text { Paraná - } \\
\text { Paraguai }\end{array}$ & $\begin{array}{c}\text { Hidrovia Paraná - } \\
\text { Paraguai }\end{array}$ & Excesso de PCHs & Excesso de $\mathrm{PCH}$ s & $\begin{array}{c}\text { Avanço da } \\
\text { fronteira } \\
\text { agricola }\end{array}$ & $\begin{array}{l}\text { Irregularidades no uso } \\
\text { e ocup ação do solo }\end{array}$ \\
\hline 5 & $\begin{array}{l}\text { Diminuição dos } \\
\text { recursos } \\
\text { pesqueiros }\end{array}$ & Mineração & $\begin{array}{l}\text { Falta de proteção/ } \\
\text { fiscalização APPs }\end{array}$ & Erosão & $\begin{array}{c}\text { A vanço da } \\
\text { fronteira agricola }\end{array}$ & $\begin{array}{l}\text { Excesso de } \\
\mathrm{PCH}\end{array}$ & M ineração \\
\hline 6 & Mineração & $\begin{array}{l}\text { Excesso de } \\
\text { PCHs }\end{array}$ & $\begin{array}{c}\text { A vanço da fronteira } \\
\text { agricola }\end{array}$ & $\begin{array}{c}\text { Avanço da } \\
\text { fronteira agricola }\end{array}$ & $\begin{array}{l}\text { Falta de proteção/ } \\
\text { fiscalização APPs }\end{array}$ & Erosão & Excesso de $\mathrm{PCH}$ s \\
\hline 7 & $\begin{array}{c}\text { Irregularidades no } \\
\text { uso e ocupação do } \\
\text { solo }\end{array}$ & $\begin{array}{l}\text { A vanço da } \\
\text { fronteira } \\
\text { agicola }\end{array}$ & $\begin{array}{l}\text { Diminuição dos } \\
\text { recursos pesqueiros }\end{array}$ & $\begin{array}{c}\text { Hidrovia Paraná - } \\
\text { Paraguai }\end{array}$ & $\begin{array}{c}\text { Irregularidades no } \\
\text { uso e ocupação do } \\
\text { solo }\end{array}$ & $\begin{array}{l}\text { A buso de } \\
\text { A grotóxicos }\end{array}$ & $\begin{array}{c}\text { Hidrovia Paraná - } \\
\text { Paraguai }\end{array}$ \\
\hline 8 & Erosão & $\begin{array}{l}\text { Abuso de } \\
\text { Agrotóxicos }\end{array}$ & M ineração & $\begin{array}{l}\text { Diminuição dos } \\
\text { recursos } \\
\text { pesqueiros }\end{array}$ & $\begin{array}{l}\text { Abuso de } \\
\text { A grotóxicos }\end{array}$ & $\begin{array}{c}\text { Diminuição dos } \\
\text { recursos } \\
\text { pesqueiros }\end{array}$ & $\begin{array}{c}\text { Falta de } \\
\text { proteção/fiscalização } \\
\text { APPs }\end{array}$ \\
\hline 9 & $\begin{array}{c}\text { Hidrovia Paraná - } \\
\text { Paraguai }\end{array}$ & $\begin{array}{c}\text { Falta de } \\
\text { proteção/fiscali } \\
\text { zação APPs }\end{array}$ & $\begin{array}{l}\text { Abuso de } \\
\text { Agrotóxicos }\end{array}$ & $\begin{array}{l}\text { A buso de } \\
\text { A grotóxicos }\end{array}$ & Mineração & Mineração & Erosão \\
\hline 10 & $\begin{array}{l}\text { Falta de proteção/ } \\
\text { fiscaliza ção APPs }\end{array}$ & $\begin{array}{l}\text { Irreg. no uso e } \\
\text { ocupação do } \\
\text { solo }\end{array}$ & $\begin{array}{l}\text { Irreg no uso e } \\
\text { ocup ação do solo }\end{array}$ & Mineração & Erosão & $\begin{array}{l}\text { Hidrovia } \\
\text { Paraná - } \\
\text { Paraguai }\end{array}$ & $\begin{array}{l}\text { Diminuição dos } \\
\text { recursos pesqueiros }\end{array}$ \\
\hline
\end{tabular}

Fonte: Construção dos autores.

\section{3 Árvores dos Sonhos}

As contribuições de todos os participantes, para a construção das árvores dos sonhos de cada uma das cidades que sediou as oficinas de elaboração do PRH-Paraguai, geraram a Figura 2, onde estão listados os vinte termos mais citados. 
Figura 2 - Árvore dos sonhos de termos mais utilizados por todos os presentes na oficina de elaboração do Plano de Recursos Hídricos da RH-Paraguai.

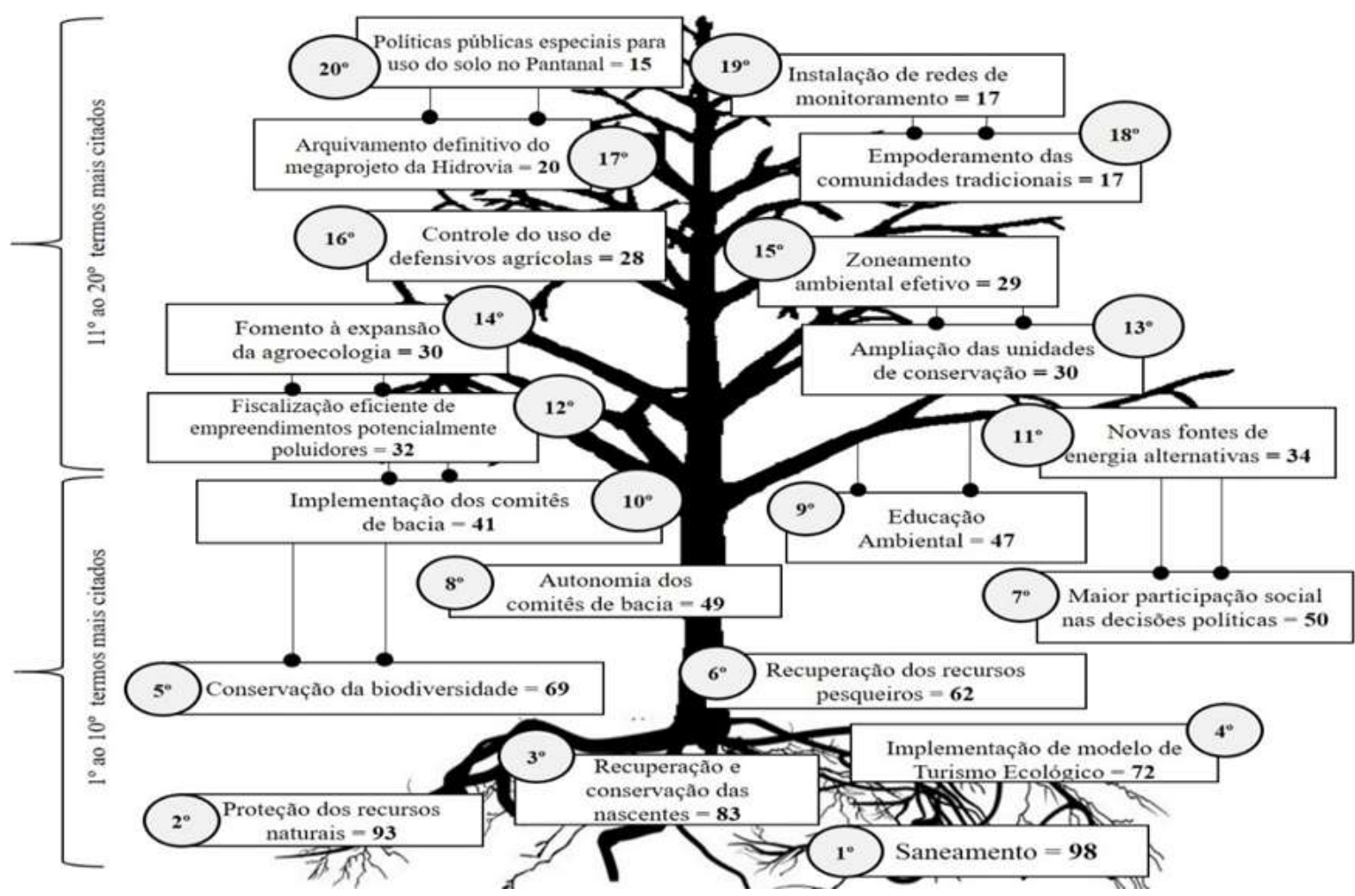

Fonte: Construção dos autores.

A partir da árvore, destacam-se dez termos que foram citados pelo menos uma vez em todas as cidades, elencados por ordem decrescente de repetições (Tabela 3). 
Tabela 3 - Ordem decrescente de citação dos 10 termos mais mencionados na Árvore dos Sonhos da oficina de elaboração do Plano de Recursos Hídricos da RH-Paraguai.

\begin{tabular}{|c|c|c|c|c|c|c|c|}
\hline $\begin{array}{l}\text { Ordem de } \\
\text { citação }\end{array}$ & $\begin{array}{c}\text { Sonhos comuns a todas } \\
\text { as cidades }\end{array}$ & Corumbá & Coxim & Bonito & Cáceres & Cuiabá & Rondon ópolis \\
\hline 1 & Saneamento & Saneamento & Saneamento & $\begin{array}{l}\text { Recuperação e } \\
\text { conservação de } \\
\text { nascentes }\end{array}$ & $\begin{array}{l}\text { Particip ação social } \\
\text { nas decisões } \\
\text { politicas }\end{array}$ & Saneamento & Saneamento \\
\hline 2 & $\begin{array}{c}\text { Proteção dos recurs os } \\
\text { naturais }\end{array}$ & $\begin{array}{l}\text { Recuperação dos } \\
\text { recursos p esqueiros }\end{array}$ & $\begin{array}{l}\text { Recuperação e } \\
\text { conservação de } \\
\text { nascentes }\end{array}$ & $\begin{array}{l}\text { Proteção dos } \\
\text { recursos naturais }\end{array}$ & Saneamento & $\begin{array}{l}\text { Recup eração e } \\
\text { conservação de } \\
\text { nascentes }\end{array}$ & $\begin{array}{l}\text { Controle do uso de } \\
\text { defensivos agricolas }\end{array}$ \\
\hline 3 & $\begin{array}{c}\text { Recuperação e } \\
\text { conservação denascentes }\end{array}$ & $\begin{array}{l}\text { Recup eração e } \\
\text { conservação de } \\
\text { nascentes }\end{array}$ & $\begin{array}{l}\text { Proteção dos } \\
\text { recursos naturais }\end{array}$ & Educação ambiental & $\begin{array}{l}\text { Recup eração dos } \\
\text { recursos } \\
\text { pesqueiros }\end{array}$ & $\begin{array}{l}\text { Novas fontes de } \\
\text { energia }\end{array}$ & $\begin{array}{c}\text { Proteção dos recursos } \\
\text { naturais }\end{array}$ \\
\hline 4 & Turismo ecológico & Turismo ecológico & $\begin{array}{c}\text { Particip ação social } \\
\text { nas decisões } \\
\text { p oliticas }\end{array}$ & $\begin{array}{c}\text { Novas fontes de } \\
\text { energia }\end{array}$ & Turismo ecológico & $\begin{array}{c}\text { Particip ação social nas } \\
\text { decisões politicas }\end{array}$ & Educação ambiental \\
\hline 5 & $\begin{array}{l}\text { Recup eração dos } \\
\text { recursos pesqueiros }\end{array}$ & $\begin{array}{l}\text { Proteção dos } \\
\text { recursos naturais }\end{array}$ & Educação ambiental & Turismo ecológico & $\begin{array}{l}\text { Recuperação e } \\
\text { conservação de } \\
\text { nascentes }\end{array}$ & $\begin{array}{c}\text { Proteção dos recursos } \\
\text { naturais }\end{array}$ & Novas fontes de energia \\
\hline 7 & Educação ambiental & $\begin{array}{l}\text { Novas fontes de } \\
\text { energia }\end{array}$ & $\begin{array}{l}\text { Controle do uso de } \\
\text { defensivos agricolas }\end{array}$ & $\begin{array}{l}\text { Controle do uso de } \\
\text { defensivos agricolas }\end{array}$ & $\begin{array}{c}\text { Empoderamento } \\
\text { das comunidades } \\
\text { tradicionais }\end{array}$ & $\begin{array}{l}\text { Recuperação dos } \\
\text { recursos pesqueiros }\end{array}$ & $\begin{array}{c}\text { Recup eração dos recurs os } \\
\text { p esqueiros }\end{array}$ \\
\hline 8 & Novas fontes de energia & $\begin{array}{l}\text { Controle do uso de } \\
\text { defensivos agricolas }\end{array}$ & Turismo ecológico & $\begin{array}{l}\text { Recup eração dos } \\
\text { recursos pesqueiros }\end{array}$ & $\begin{array}{l}\text { Novas fontes de } \\
\text { energia }\end{array}$ & Turismo ecológico & $\begin{array}{c}\text { Recup eração e } \\
\text { conservação de nascentes }\end{array}$ \\
\hline 9 & $\begin{array}{l}\text { Controle do uso de } \\
\text { defensivos agricolas }\end{array}$ & Educação ambiental & $\begin{array}{l}\text { Recup eração dos } \\
\text { recursos p esqueiros }\end{array}$ & $\begin{array}{l}\text { Emp oderamento das } \\
\text { comunidades } \\
\text { tradicionais }\end{array}$ & $\begin{array}{l}\text { Controle do uso de } \\
\text { defensivos } \\
\text { agricolas }\end{array}$ & $\begin{array}{l}\text { Emp oderamento das } \\
\text { comunidades } \\
\text { tradicionais }\end{array}$ & $\begin{array}{l}\text { Participação social nas } \\
\text { decisões p oliticas }\end{array}$ \\
\hline 10 & $\begin{array}{c}\text { Emp oderamento das } \\
\text { comunidades tradicionais }\end{array}$ & $\begin{array}{c}\text { Emp oderamento das } \\
\text { comunidades } \\
\text { tradicionais }\end{array}$ & $\begin{array}{c}\text { Empoderamento das } \\
\text { comunidades } \\
\text { tradicionais }\end{array}$ & $\begin{array}{c}\text { Participação social } \\
\text { nas decisões } \\
\text { p oliticas }\end{array}$ & $\begin{array}{l}\text { Educação } \\
\text { ambiental }\end{array}$ & Educação ambiental & $\begin{array}{l}\text { Emp oderamento das } \\
\text { comunidades tradicionais }\end{array}$ \\
\hline
\end{tabular}

Fonte: Construção dos autores.

A comparação entre as cidades por meio das respostas, no muro de lamentações, mostrou pela análise de agrupamento (Cluster analysis), haver similaridade entre a lista das lamentações das cidades de Cáceres e Cuiabá em 50\% e com Rondonópolis e Coxim em 40\% de similaridade entre as respostas (Figura 3). 
Figura 3- Cluster similaridade Muro das lamentações.

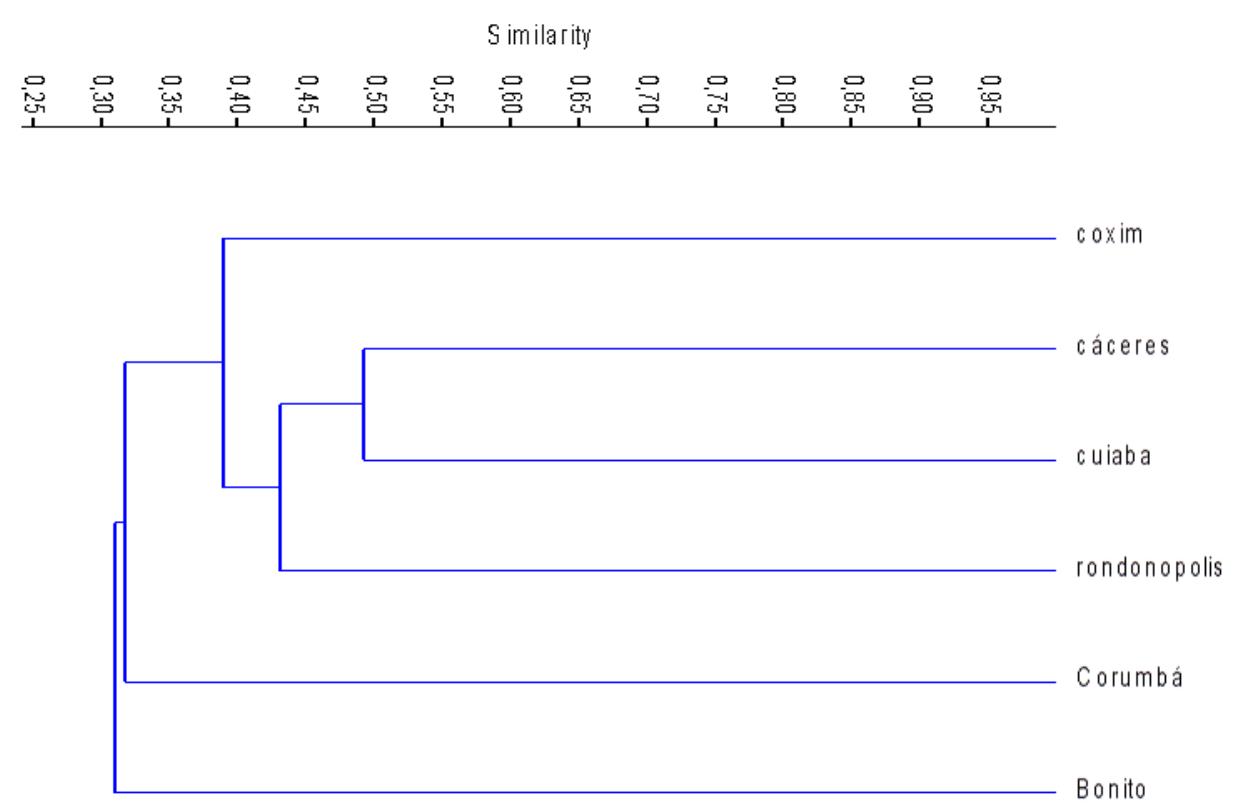

Fonte: Construção dos autores.

Em relação a semelhança de respostas, entre as cidades na arvore dos sonhos, a análise de agrupamento (Cluster analysis), indicou haver similaridade entre as cidades de Cáceres e Cuiabá em $50 \%$ e com Rondonópolis e Coxim em $40 \%$ de similaridade (Figura 4).

Figura 4- Cluster similaridade arvore dos sonhos

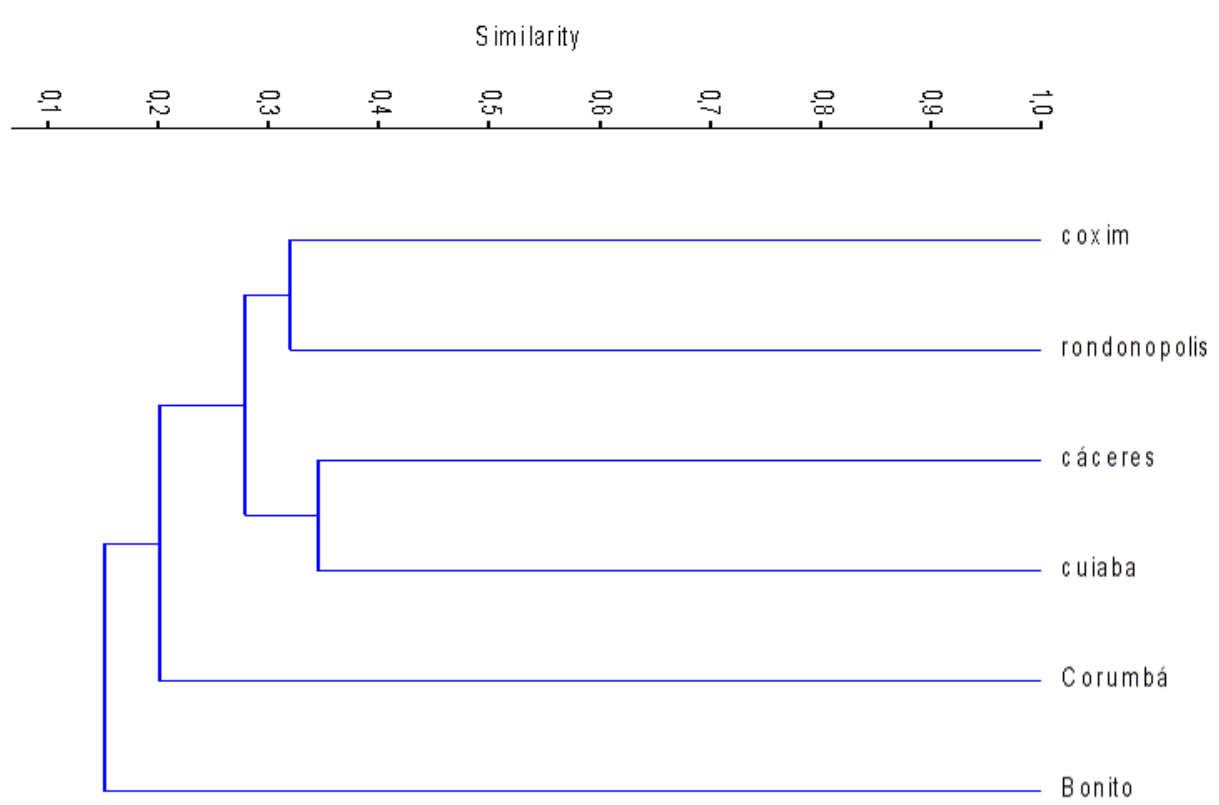

Fonte: Construção dos autores.

\section{Discussão}

O predomínio da sociedade civil frente aos demais grupos sociais nas cidades de MT, foi mais evidente em Cáceres, que se equiparou à capital Cuiabá, mesmo tendo uma população muito menor, o que pode ser atribuído à proximidade do rio 
Paraguai nesta cidade, à forte dependência e à relação que a população tem com o rio Paraguai (turismo e pesca) (Da Silva et al. 2001). Esta condição gera aos seus munícipes maior apego à territorialidade, conceito que incorpora os limites geográficos territoriais às relações econômicas, culturais, o modo como elas próprias se organizam no espaço e como elas dão significado ao lugar que habitam (Raffestin, 1993). De modo geral, a presença majoritária do grupo sociedade civil em todo MT pode ser atribuída ao posicionamento estratégico e geográfico das principais cidades do Estado dentro da RH-Paraguai. Enquanto que em MS, a capital do Estado, Campo Grande, possui sua área urbana fora dos limites da região hidrográfica, diminuindo assim o acesso de um grande número de habitantes nas decisões da bacia. Porém, é preciso ressaltar que a escolha das cidades a sediarem o evento de elaboração do plano pode, ainda que indiretamente, excluir a participação de partes interessadas nas políticas públicas para a região hidrográfica, uma vez que não houve subsídios de deslocamento das pessoas de suas comunidades até o local do evento.

A política nacional de recursos hídricos, a Lei 9433/97, trouxe grandes avanços para a gestão das águas brasileiras, entre eles estão a proposição do tripé: descentralização, integração e participação social, que deve sustentar o planejamento e a gestão destes recursos (Santos et al. 2020). Contudo, a paridade entre os aspectos técnicos, sociais, políticos e ambientais necessários para a elaboração do Plano de Recursos Hídricos ainda é um dos maiores desafios encontrados. No caso analisado, a mediação do evento atuou de modo a evitar conflitos entre os diferentes usuários presentes, essa ação desarticula os grupos na presentes e prejudica a identificação de conflitos e similaridades entre os atores sociais, não houve negociação entre as demandas. Para Santos e Saito (2006) a minimização de situações-problema na aplicação da participação social desvirtua os propósitos do conceito.

Nas oficinas realizadas em MS, em Coxim onde a adesão da Universidade Estadual foi maior ao convite, a participação da sociedade civil foi destaque, sendo esta cidade a única exceção na qual o poder público não foi maioria dos presentes nas oficinas neste Estado. Neste sentido, é importante ressaltar que as universidades atuam como um catalizador da participação de lideranças, grupos, associações e ONG's, visto que Cáceres-MT também apresentou presença semelhante neste grupo social e é o município onde está localizada a sede da Universidade do Estado de Mato Grosso. Corumbá e Bonito - MS foram as cidades com menor número de presença, apesar de serem municípios de grande importância no contexto econômico da bacia, por se tratarem de polos do turismo nas modalidades ecoturismo e pesca, respectivamente. A convocação para participar das oficinas foi realizada através de duas frentes de divulgação. Diretamente por telefone e e-mail, a Partners, empresa contratada para mobilização e divulgação, entrou em contato com a lista de lideranças comunitárias e representantes de entidades, disponibilizada pelo grupo de acompanhamento do plano e por alguns comitês de bacia no Mato Grosso do Sul. E indiretamente, através da veiculação em meios de comunicação das cidades, rádio e TV. Nas três cidades houveram momentos de conflito, que foram prontamente contornados pelas equipes de apoio e organização dos eventos. Representantes dos Usuários da água bruta, ligados ao agronegócio, questionaram as informações apresentadas sobre fósforo e Demanda Bioquímica de Oxigênio (DBO), enquanto que membros da sociedade civil reclamaram que algumas áreas específicas estariam sendo negligenciadas pelo diagnóstico. Nesses momentos embate entre os grupos sociais, a ANA desapoderou-se da oportunidade de se aprofundar nas causas reais dos problemas socioambientais da região através da participação efetiva e da negociação de interesses hídricos.

A problemática do Saneamento foi a principal menção dos participantes, quando analisada todas as cidades (exceto Bonito-MS). Foram 305 menções ao todo. Por ocupar esta colocação, as questões de infraestrutura que compõe os serviços de saneamento básico, indicam grande carência de cobertura e eficiência de tais serviços dentro da RH-Paraguai.

Uma pesquisa realizada em 2018 pelo Instituto Trata Brasil, propõe um ranking comparativo entre todos os Estados brasileiros e aponta que os Estados de Mato Grosso e Mato Grosso do Sul apresentam avanços muito pequenos nessa questão. Este estudo, porém, considera apenas os 100 maiores municípios brasileiros, deixando de contemplar a maioria dos 
pertencentes à RH Paraguai. Esta condição representa, portanto, uma das principais ameaças à qualidade dos corpos d'água da RH-Paraguai, motivando o desenvolvimento de um projeto denominado "Pacto em Defesa das Cabeceiras do Pantanal", com atuação em 25 municípios de Mato Grosso, com ações para a melhoria do saneamento na região (WWF, 2001).

Diversos estudos tem sido realizados nos rios da RH-Paraguai que drenam áreas urbanas, apontando a degradação da qualidade da água pelo uso do canal como local de disposição e diluição de efluentes domésticos (Lima e Rondon Lima, 2009; Dias et al. 2011; Bezerra et al. 2011). Segundo dados do Relatório de Qualidade de Água da RH-Paraguai, a maioria dos córregos urbanos que drenam as grandes cidades possuem IQA (Índice de Qualidade da Água) entre regular e péssimo, evidenciando a deterioração ambiental dos recursos hídricos nesta região (ANA, 2016). Tal degradação intensifica principalmente os conflitos com os usuários da água para balneabilidade e hidro turismo.

No município de Bonito, os serviços que integram a problemática do saneamento ocuparam a $6^{\circ}$ colocação, reflexo da atuação da Empresa de Saneamento de Mato Grosso do Sul (SANESUL), em parceria com o Governo do Estado de Mato Grosso do Sul, que investiu aproximadamente $\mathrm{R}$ \$ 4,5 milhões na manutenção e ampliação dos serviços de saneamento entre 2015 e 2019, alcançando a meta de fornecimento de água universalizado e uma das maiores coberturas de esgotamento sanitário do Estado, 98\% (Sanesul, 2019). Investimento este justificável pelo incremento no hidro turismo nesta cidade.

A posição de destaque que a problemática do saneamento apresentou na maioria das oficinas realizadas pode ser explicada pelo fato de a consulta pública ter atingido apenas a região urbana da bacia, já que esta é uma questão relacionada aos centros urbanos.

O muro das lamentações construído em Bonito diverge das demais em relação ao saneamento. Nesta cidade a primeira posição ficou com 'Falta de proteção/fiscalização em áreas de proteção permanente - APPs', indicando um conflito importante entre as atividades econômicas mais proeminentes na região: turismo e agropecuária. Harris et al. (2005) asseguram que a alteração na cobertura do solo em APPs na bacia do rio Formoso, principal rio que drena este município, entre os anos de 1989 e 2005, aumentaram drasticamente com a intensificação das áreas destinadas à agropecuária, com consequente decréscimo das áreas de matas e cerrado, que além de diminuir a fauna e flora da bacia, traz sérias consequências para os rios cênicos da região. Com isso o avanço da agricultura na cidade de Bonito está associado ao assoreamento dos rios, ameaçando o tom cristalino das águas da região, peculiaridade que a insere na rota do ecoturismo brasileiro (Armôa, 2019; Paschoal, 2019).

Para os participantes da cidade de Coxim, o segundo maior desafio enfrentado, após a questão do Saneamento, é a 'Erosão'. A região de Coxim, localizada na sub bacia Alto Taquari, é uma das áreas que apresentam os maiores potenciais erosivos da RH-Paraguai (Risso et al. 1997 e Galdino et al. 2004). A predisposição natural da bacia, somada à expansão agrícola sem a adoção de práticas de manejo conservacionistas do solo, contribuem para que os processos erosivos se intensifiquem. Essa sub bacia produz uma quantidade de sedimentos da ordem de 10.950.000 t/ano (PAE, 2004), e causam vários impactos, como a redução de sua produção pesqueira (Catella, 2005).

O avanço da fronteira agrícola é um aspecto mencionado no Muro das Lamentações que tem relação com diversos outros itens também mencionados como, por exemplo, a erosão do solo. Este termo alcançou o $6^{\circ}$ lugar em Coxim e em Bonito e a $3^{\circ}$ posição em Rondonópolis. Galdino et al. (2004) aponta que muitas ações para diminuição do desmatamento para o plantio na sub bacia do rio Taquari foram desenvolvidas a partir dos anos 2000, porém estes esforços ainda são insipientes para frear o desmatamento e a ascensão das monoculturas na região. A situação é semelhante na sub bacia do rio São Lourenço, onde estão inseridas cidades com intensa atividade rural, predominantemente agricultura, em acelerado crescimento, como Itiquira, Campo Verde, Jaciara, entre outras que apresentaram suas demandas através da oficina de Rondonópolis, dando destaque à questão no ranking.

A análise da dinâmica do Muro das Lamentações demonstrou ainda que o grande número de empreendimentos hidrelétricos instalados na RH-Paraguai, 46 empreendimentos encontram-se implantados, é uma preocupação dos atores 
sociais, apontada em todas as oficinas. Souza Filho (2013) alerta que os modelos utilizados para previsão de impactos ambientais destes empreendimentos são incipientes, pois a exigência de estudos é relativamente nova e, além disso, não consideram as especificidades e fragilidades dos sistemas fluviais. No caso da RH-Paraguai, o pulso de inundação do Pantanal requer um olhar sistêmico da bacia, para que a principal dinâmica ecológica, responsável pelas características do local seja preservada.

A instalação de hidrelétricas causa a fragmentação de rios, que é apontado em diversos estudos como o maior impacto para o sistema hídrico do Pantanal, cuja característica principal é o dinâmico fluxo das águas e a sua sazonalidade. As intervenções no fluxo hídrico fragmentam habitats, alteram a biodiversidade e impedem a migração reprodutiva de peixes, além de, em alguns casos, reter água, nutrientes e sedimentos, alterando o curso natural desses elementos que são necessários para o funcionamento dinâmico de uma planície de inundação. (Junk, 1989; Fiori e Ciali, 1999; Fiori et al. 2001; Paranhos et al. 2003; Grizio e Souza Filho, 2010; Calheiros et al. 2018).

O sonho da construção de obras de infraestrutura que resolvam os problemas de saneamento básico em toda bacia, teve maior destaque, alcançando o primeiro lugar em quatro das seis cidades que receberam os eventos, coerente com os resultados do Muro das Lamentações, o que indica que é um problema que afeta a população, gerador de conflitos de usos da água e de saúde pública (Oliveira, 2005; Magalhães Filho e Paulo, 2017). Apenas Cáceres e Bonito apresentaram variação neste sentido.

Os integrantes das oficinas de construção do Plano incluíram a participação social nas decisões políticas como um dos itens principais de suas Árvores dos Sonhos, particularmente na oficina efetuada em Cáceres, o que indica que a regulamentação desta participação como um dos fundamentos da Lei das Águas não é suficiente para que a maioria dos grupos sociais se sinta de fato representado nas decisões políticas da região. A Política Nacional dos Recursos Hídricos traz como um de seus fundamentos a gestão participativa e descentralizada, com o objetivo de promover o diálogo entre atores sociais e, desta forma, construir efetivamente a governança das águas.

Entre os termos comuns em todas as oficinas, este item ocupou a $6^{\circ}$ colocação e, quando analisado pontualmente, $\mathrm{o} 1^{\circ}$ lugar na cidade de Cáceres e o $4^{\circ}$ lugar nas cidades de Coxim e Cuiabá, expressando que a expansão dessa participação, de modo que alcance os grupos sociais mais isolados e considere as diversas realidades que compõe a bacia, é uma demanda bastante evidente. $\mathrm{O}$ incremento desta participação social nas decisões políticas como principal sonho ocorreu justamente em Cáceres, onde a presença da sociedade civil, através de associações, pescadores e ribeirinhos, foi muito significativa nas oficinas.

Na cidade de Bonito o sonho com o maior número de repetições foi o de nascentes conservadas e protegidas, coerente com os resultados do Muro das Lamentações, sendo essa uma cidade onde a economia depende, em grande parte, do turismo ecológico (Lomba e Lamoso, 2005), que se conecta ao desejo de expansão da atividade e acréscimo do PIB local, também mencionados.

As cidades de Corumbá e Cáceres são cidades com intenso turismo de pesca, notada particularmente no ranking de sonhos, ao classificarem a recuperação dos recursos pesqueiros entre os três primeiros colocados. A pesca é uma das atividades mais tradicionais na região do Pantanal. Diversas famílias obtêm seu sustento, direta ou indiretamente, do exercício desta pratica milenar, tanto que em todas as cidades consultadas os participantes mencionaram este anseio. Desvinculado deste importante contexto socioeconômico, o governo de Mato Grosso propôs um projeto de Lei (PL 460/2017) que proibiria a pesca por 5 anos em qualquer modalidade, ou seja, tanto pesca de subsistência quanto profissional ou recreativa em todo o Estado. Após intensas manifestações e pressão contrária, o governo decidiu recuar do projeto. Diversos conflitos entre os pescadores ribeirinhos e empresários do turismo, bem como adeptos da pesca esportiva surgiram no debate deste projeto, principalmente sobre a forma de aplicação da pretensa Lei e a sua fiscalização (Carvalho, 2018; Assunção, 2019). 
O turismo é uma atividade econômica expressiva na RH Paraguai, base de diversas economias locais, com destaque ao Pantanal à região de Bonito-Jardim (MS) e o Parque Nacional da Chapada dos Guimarães (MT).

A relevância dessa atividade enquanto turismo ecológico foi destacada na $4^{\circ}$ colocação da Árvore dos Sonhos, na qual os participantes das oficinas indicaram que há a necessidade de regulamentar as bases sustentáveis para a exploração turística da região, destacadamente em Corumbá e Cáceres. Trentin e Gruber (2006) mencionam que o maior desafio ao planejamento do turismo da região é o aprimoramento dos instrumentos norteadores e indicadores de sustentabilidade, para que a sustentabilidade econômica, social e ambiental seja um dos produtos do desenvolvimento desta atividade.

Toda a bacia possui alto potencial turístico, porém nem todos os municípios exploram esta atividade de modo rentável. Salvati (2004) aponta que o turismo ecológico respeita as culturas locais e dele provem benefícios e oportunidades para as comunidades locais, além de contribuir para a conservação do meio ambiente. Sendo assim o turismo se apresenta na RH-Paraguai como uma oportunidade, tanto econômica quanto ambiental. A magnitude e a importância socioambiental desta atividade requerem que sejam considerados princípios de conservação e sustentabilidade na elaboração e implementação do planejamento e desenvolvimento destas atividades antrópicas (Calheiros e Ferreira, 1997; Agostinho et al. 2008)

Dentre os termos comuns entre as dinâmicas realizadas em todas as cidades, destaca-se ainda o $2^{\circ}$ colocado Proteção dos recursos naturais e o $3^{\circ}$ Recuperação e conservação de nascentes. Considerando o predomínio dos biomas Cerrado e Pantanal na RH-Paraguai, que possuem elevada biodiversidade e são de vital importância para a conservação da água doce em todo país. Porém, as pressões causadas pela ocupação desordenada das áreas no planalto, onde predomina o cerrado, provoca sérios danos ambientais econômicos e sociais ao frágil ecossistema, uma vez que, constituem as maiores regiões de fronteira agrícola e de desenvolvimento econômico de base florestal, como mencionado anteriormente (Brasil, 2010; Brasil, 2017). Esta demanda evidenciada através da Árvore dos Sonhos indica que a ocupação dessas áreas da região hidrográfica é caracterizada pela desvalorização da vegetação nativa em favor da expansão das áreas de produção agropecuária, do aumento da demanda por produtos florestais de maneira pouco sustentável.

Entre os 20 termos mais citados como sonhos para o futuro ambiental da RH-Paraguai, destaca-se o anseio pela estruturação eficaz dos comitês de bacia, que aparece duas vezes na lista, $8^{\circ}$ e $10^{\circ}$ lugares, solicitando a implementação e a autonomia dos comitês dentro da bacia hidrográfica. Atualmente, a região hidrográfica possui seis comitês instalados (CBHs Sepotuba, Cabaçal, São Lourenço, Margem Esquerda do Rio Cuiabá - MT e Miranda - MS). Esta demanda indica que, apesar de possuir seis comitês instalados na RH-Paraguai, a atuação individual dos mesmos é insipiente. Vários estudos efetuados em comitês brasileiros apontam lacunas e oportunidade para defender interesses próprios (Jacobi, 2005; Fracalanza et al., 2009).

Além disso, não existe um comitê integrado de toda a RH-Paraguai. Os Comitês de Bacia Hidrográfica exercem um papel estratégico na gestão das águas, especialmente por ser uma espécie de arena decisória composta pelos atores sociais originários do território, ou seja, da bacia hidrográfica em questão (Mesquita, 2018). Em grandes bacias hidrográficas, como é o caso da RH-Paraguai, o comitê integrado é de suma importância, pois possibilitaria o diálogo entre os conflitos de uso da água e aproximar as demandas dos usuários das comunidades locais com a tomada de decisão. A exemplo disso, a região hidrográfica do rio São Francisco possui um Comitê Executivo de Estudos Integrados (CEEIVASF), que integram os estados de Minas Gerais, Bahia, Pernambuco, Paraíba, Alagoas, Sergipe e o Distrito Federal e, para o exercício da descentralização, contam ainda com subcomitês distribuídos por toda bacia (Gomes, 2008; Mesquita, 2018).

Abers e Keck (2004) reforçam que a natureza participativa dos comitês rompe com as tradicionais fronteiras políticoadministrativas entre municípios, estados e União, fortalecendo a discussão sobre a democratização das políticas públicas e, através da territorialidade, tornando mais democrático o processo de decisão sobre os usos múltiplos e a proteção dos recursos hídricos. Com isso, o efetivo funcionamento dos comitês atende aos objetivos e diretrizes da Política Nacional de Recursos Hídricos quanto à descentralização e participação social na gestão das águas. 
A necessidade de fortalecer e aperfeiçoar a fiscalização esteve presente em $12^{\circ}$ lugar no ranking de sonhos dos participantes, corroborando com Leandro et al. (2013), que afirma que a fragilidade e dinâmica do corredor fluvial e as diversas áreas de preservação permanente ao longo do rio Paraguai requerem o aumento do número de ações de fiscalização.

Em $13^{\circ}$ lugar, Ampliação das unidades de conservação foi citado 30 vezes e apareceu apenas nas cidades de Cáceres, Coxim, Corumbá e Bonito. Em Cáceres há a Estação Ecológica de Taiamã, reconhecida em 2018 como sítio Ramsar pela Conferência das Partes na Convenção sobre Zonas Úmidas de Importância Internacional em Dubai nos Emirados Árabes, e possui solicitação por parte do ICMBio de ampliação de sua área total. Em Coxim está a APA Rio Cênico, Corumbá possui duas unidades, a Estrada Parque Pantanal e o Parque Estadual do Pantanal Negro, e em Bonito, estão o Monumento Natural Gruta do Lago Azul e Monumento Natural do Rio Formoso (Longo e Torrecilha, 2014).

Com 30 citações, os participantes das cidades de Corumbá e Cáceres demandaram a expansão das técnicas agroecológicas, seguindo a tendência mundial de sustentabilidade proposta pela Organização das Nações Unidas - ONU, através dos ODS - Objetivos do Desenvolvimento Sustentável, que apresentam 17 metas para a sustentabilidade, destacando para este item citado na dinâmica o objetivo 2: Fome zero e Agricultura Sustentável.

A Embrapa Pantanal, com sede em Corumbá, produziu em 2004 o documento Princípios de agroecologia no manejo das pastagens nativas do Pantanal que pretende ampliar a ótica agrícola para uma visão holística do agro ecossistema pantaneiro, contribuindo para torná-lo produtivo, econômico e ecologicamente sustentável (Santos et al. 2004). O maior desafio na RH-Paraguai é realocá-la como uma unidade especial para o planejamento e a gestão dos recursos naturais, água, solo e biodiversidade e, consequentemente, frear os processos de degradação que ocorrem pela busca do desenvolvimento regional com práticas que a tratem de acordo com suas especificidades.

Em todas as cidades de MT os participantes citaram que o cenário dos sonhos para a bacia não comporta o projeto da hidrovia Paraná - Paraguai. Estudos apontam que este projeto afetará gravemente o pulso de inundação na região, mudando completamente a dinâmica hídrica, responsável pela diversidade ecológica dos ecossistemas aquáticos e terrestres (Da Silva e Silva, 1992; Ponce, 1995; Hamilton, 1998; Migliacio, 2001).

Este sonho é comum também às cidades de Corumbá e Coxim no Mato Grosso do Sul. A proposta desta hidrovia teve início em 1987, unindo os interesses dos países da Bacia do Prata: Bolívia, Brasil, Paraguai, Uruguai e Argentina. O projeto propôs obras de dragagem, alteração no curso do rio, retificação de curvas e intenso tráfego comboios de transporte de soja, milho, arroz, madeira, minérios de ferro e manganês e cimento nos rios Paraná e Paraguai, ininterruptamente, ou seja, 24 horas por dia durante todo ano, do município de Cáceres-MT até Nueva Palmira, no Uruguai (Ponce, 1995; Silva, et al. 2004; Moreira, 2018).

A incorporação de novas fontes de energia como alternativa à matriz atual, baseada em hidroeletricidade, é outro sonho da população e esteve presente em todas as árvores construídas. Hoje, a RH-Paraguai conta com 46 empreendimentos hidrelétricos em operação, além de quatro em fase de construção, sete outorgados e onze em estudos para instalação, ao reter a água e depois soltá-la para gerar energia, as usinas hidrelétricas e PCHs alteram toda a dinâmica do rio Paraguai. Isto levou a equipe coordenadora do Plano a contratar um trabalho específico e complementar, envolvendo mais de 50 pesquisadores, para avaliar por analise multicritério, o efeito das atuais e estimar os efeitos das futuras hidrelétricas sobre os rios e, principalmente sobre o Pantanal (ANA, 2017).

A necessidade do controle sobre o uso de defensivos agrícolas permeou todas as oficinas realizadas, especialmente em Rondonópolis, onde alcançou o segundo lugar entre os mais citados. Esta cidade está entre as maiores produtoras de produtos agropecuários do país (Santos, 2016). Por estar situada na porção do planalto (parte alta), as atividades antrópicas potencialmente poluidoras, como o abuso de defensivos afetam diretamente o Pantanal através do escoamento superficial. Estudos que monitoraram a região no período de 2012 a 2014 constaram que 58\% das áreas naturais no Planalto da bacia 
foram drasticamente alteradas pelo uso antrópico na atividade agropecuária.

Mato Grosso é considerado campeão nacional em consumo de agrotóxicos, sendo que, dos seus 141 municípios, 24 produzem $90 \%$ dos produtos agrícolas e consomem 90\% dos agrotóxicos e fertilizantes químicos consumidos no Estado (Pignati e Machado, 2011). Entre 2012 e 2014, foi usado em média 191.439 toneladas por ano de agrotóxicos em Mato Grosso (Bombardi, 2017), não existem dados específicos na RH-Paraguai. São raros os estudos sobre os efeitos negativos do uso de agrotóxicos, especialmente no Pantanal. O uso abusivo de agrotóxicos é um dos conflitos ambientais identificados na RHParaguai que tem relação com a água, envolvendo de um lado, indígenas e pequenos fazendeiros e de outro lado os grandes produtores rurais (Silva, 2018). A aplicação contínua destes compostos químicos é indispensável ao modelo de monocultura anual de grão que ocorre principalmente nos municípios de Rondonópolis, Bonito e Coxim dentre os que participaram das oficinas, como citado anteriormente.

Todas as cidades apontaram que o empoderamento das comunidades tradicionais pantaneiras é um grande desejo para o futuro ambiental. Silva e Silva (1992) afirmam que as comunidades tradicionais são um patrimônio cultural e que estão envolvidos em todos os setores da economia local. Porém, os conhecimentos tradicionais poderiam ser melhor aproveitados se fossem mais envolvidos na gestão das atividades econômicas e políticas públicas regionais. A efetividade da gestão participativa se dá através do exercício do diálogo que visa incluir todos os setores e grupos que estão envolvidos em uma questão, compartilhando conhecimentos específicos, identificando, coletivamente, os desafios, planejando ações e tomando decisões que beneficiem o coletivo. No Brasil, as bases legais para o desenvolvimento de um ambiente político social que integrem mecanismos de participação popular na gestão pública foram, inicialmente propostas, pelo processo de redemocratização ocorrido no ano de 1988, com a promulgação da Constituição Brasileira e, posteriormente, nas políticas ambientais e de recursos hídricos, que preveem foros de participação social, como os comitês de bacias hidrográficas, mencionados acima.

O que efetivamente ficou evidenciado nas duas dinâmicas realizadas nas oficinas foram os conflitos socioambientais, e a necessidade de se compatibilizar economia e ambiente, interesses públicos, coletivos, difusos e privados, no atual contexto econômico (Rossi e Santos, 2018), onde a produção agrícola e de energia (hidrelétrica), tem sido reprodutor e gerador de conflitos cada vez mais graves e frequentes. Estes conflitos vivenciados pela população precisam ser considerados na construção de um Plano de Recursos Hídricos e para tanto, é preciso vencer as dificuldades que se apresentam ao atendimento das negociações, disposições e diretrizes apontadas pelos grupos sociais no momento da consulta pública. Acessar as informações atualizadas, proporcionar o deslocamento das pessoas para participar das diversas atividades e lidar com questões sociais e ambientais que representam diferentes interesses na área da bacia, de ordem técnica podem ser fatores limitantes à eficiência da governança das águas construída através da execução das ações previstas pelo Plano (Pereira, 2003; Fracalanza e Campos, 2010; Santos, 2020).

\section{Conclusão}

A metodologia aplicada neste estudo permitiu registrar fragilidades na participação social nas oficinas de construção do PRH-Paraguai.

Fica evidente, no entanto, que a presença dos atores sociais nas oficinas de elaboração do PRH-Paraguai não é garantia de efetiva participação social, tal qual é previsto pela Lei das Águas, Lei n 9.433/1997. A condução das metodologias aplicadas e o tempo corrido destinado à fala e a contribuição dos participantes é insuficiente para que todos se sintam confortáveis a se posicionar. Todavia, a composição dos grupos sociais presentes não inclui todas as partes interessadas, visto que não foi destinado nenhum tipo de auxilio deslocamento para membros da sociedade civil pertencentes a comunidades distantes dos locais escolhidos para sediar os eventos. Evidenciando a ausência de um processo verdadeiramente democrático e 
participativo desde a sua formulação. A ausência de grandes produtores rurais nessa construção também é uma fragilidade. E evidencia o desejo da manutenção se seu poder de influência e decisão, afinal, possuem voz e grandes vantagens na sociedade, diferente dos grupos de comunidades tradicionais e pequenos produtores. É necessário ainda a presença de grupos de políticos eleitos, participando de eventos consultivos como este, já que são os que devem ser pressionados para que as mudanças ocorram.

Além disso, ainda sobre a efetividade da participação social, cabe destacar que seria necessário realizar oficinas em outros municípios dentro da região hidrográfica em questão, que é composta por 86 cidades. Reconhecer e incluir as demais regiões é um mecanismo de compensar desigualdades e assegurar a expressão dos interesses dos setores menos favorecidos, evitando que os processos de participação sejam utilizados apenas como legitimador de decisões previamente tomadas por setores e cidades já privilegiados econômica e socialmente.

Este estudo permitiu a identificação dos seguintes conflitos: i) entre o setor elétrico e a sociedade civil, no que diz respeito à quantidade de usinas instaladas na região do Pantanal e a influência delas para o pulso de inundação; ii) entre a população nativa, moradores locais e pescadores profissionais, que almejam por participarem mais diretamente das decisões ambientais e que estão concentradas em outras instâncias de poder, desconsiderando os saberes que possuem e a forte conexão com o ambiente pantaneiro e iii) a dificuldade de acesso ao pescado pelos pescadores profissionais nativos, devido às atividades antrópicas nas partes altas da bacia.

A participação social nas oficinas demonstrou como os cidadãos podem estabelecer diálogo com as diversas instâncias da administração pública federal, instituindo, dessa forma, um modelo de governança para o planejamento e a gestão dos recursos hídricos. A utilização de oficinas como ferramenta metodológica apontou que este instrumento mediador é nitidamente compreendido pelos principais grupos sociais presentes nas atividades de elaboração do PRH Paraguai, tanto quanto a percepção da importância da participação ativa nesses eventos quanto ao entendimento do conceito em si. Neste sentido os grupos com melhor capacitação técnica (governo, mercado e professores) apresentaram melhor compreensão destes dois aspectos investigados sobre governança e participação social. Os pescadores e a comunidade em geral, mesmo que não dominem o conceito, atribuem a devida importância à discussão.

Contudo, para que se consiga uma gestão dos recursos hídricos pautada na descentralização, participação e integração, recomenda-se que se aumente a visibilidade do setor de recursos hídricos na agenda política nacional, assim como, realizar ações para fortalecer e reformular as instituições de bacias para tornar o engajamento dos agentes envolvidos mais e efetivo e orientado para resultados que venham d a interação com os municípios de uma determinada baia hidrográfica, para uma melhor coordenação entre as políticas de recursos hídricos e políticas urbanas (considerar entre estados e municípios; incentivos para fóruns participativos) criando oportunidades para a troca de experiências entre estados e bacias hidrográficas para aprender, uns com os outros, sobre os resultados, progressos e desafios, relacionados a gestão dos recursos hídricos. Além disso, é preciso que se desenvolva mecanismos que garantam nas reuniões anuais de comitês de bacias hidrográficas e de conselhos estaduais de recursos hídricos, a presença dos atores e grupos sociais interessados, tal qual é previsto pela Lei das Águas, Lei $n^{\circ} 9.433 / 1997$.

\section{Agradecimentos}

Agradecemos a Universidade do Estado de Mato Grosso e programa Pós Graduação em Ciências Ambientais pela oportunidade de qualificação profissional; ao Projeto Corredor Ecológico, econômico e cultural do Rio Paraguai/ Processo: FAPEMAT.0308817/2017 pelo apoio financeiro na pesquisa, contribuição $\mathrm{N}^{\circ} 9$.

"O presente trabalho foi realizado com apoio da Coordenação de Aperfeiçoamento de Pessoal de Nível Superior Brasil (CAPES) - Código de Financiamento 001”. bolsa concedida a primeira autora. E ao CNPq, pela bolsa de produtividade 
científica a $4^{\mathrm{a}}$ autora.

\section{Referências}

Abers, R. \& Keck, M.(2004). Comitês de Bacia. Uma abordagem política no estudo da participação social. Revista de estudos urbanos e regionais, 6(1), 5568.

Agência Nacional Das Águas - ANA. (2017). Plano de Recursos Hídricos da Região Hidrográfica do Paraguai - PRH Paraguai: Diagnóstico Consolidado da Região Hidrográfica do Rio Paraguai - Versão Preliminar. Agência Nacional de Águas - Brasília: ANA/SPR, Engecorps Engenharia S.A.

Agostinho, A. A.; Pelicice, F.M \& Gomes, L. C.(2008). Dams and the fish fauna of the neotropical region: impacts and management related to diversity and fisheries. Brasilian Journal of Biology, 68, p.1119-1132.

Almeida, F.F.M. (1945). Geologia do sudoeste matogrossense. Brasil. Div. Geol. Miner., B., Rio de Janeiro, no 116, 9-115.

Araújo, J.B.S.; Silva, C.J.; \& Santana, C.G. (2015). Oficina do Futuro como Metodologia de Formação Inicial com Alunos do PIBID. Anais... $8^{\circ}$ Encontro Internacional de Formação de Professores (ENFOPE) e $9^{\circ}$ Fórum Permanente de Inovação Educacional (FOPIE).

Armôa, M.(2019). Decreto disciplina manejo do solo nas propriedades rurais de Bonito e Jardim. Campo Grande. Governo do Estado de Mato Grosso do Sul. http://www.ms.gov.br/decreto-disciplina-manejo-do-solo-nas-propriedades-rurais-de-bonito-e-jardim/ .

Assunção, H. (2019). Assembleia Legislativa discute alterações à Lei da Pesca. Secretaria de Comunicação Social. CUIABÁ. 2019. https://www.al.mt.gov.br/midia/texto/387/deputado/assembleia-legislativa-discute-alteracoes-a-lei-da-pesca/visualizar.

Bezerra, J. P. P.(2011). A água como elemento estruturante na construção de territórios da soberania alimentar. Presidente Prudente:NERA - Núcleo de Estudos, Pesquisas e Projetos de Reforma Agrária. DATALUTA, p.1-17.

Bolson, S. H.; \& Haonat, A. I.(2016). A governança da água, a vulnerabilidade hídrica e os impactos das mudanças climáticas no brasil. Belo Horizonte. Veredas do Direito, 13(25), 223-248.

Bombardi, L. M.(2013). Agrotóxicos: uma arma silenciosa contra os direitos humanos. Direitos humanos no Brasil 2013: Relatório da Rede Social de Justiça e Direitos Humanos. São Paulo.

Brasil.(1997). Lei n. 9.433, de 8 de janeiro de 1997. http://www.planalto.gov.br/ccivil_03/LEIS/L9433.

Brasil.(2017). Ministério do Meio Ambiente. Secretaria de Recursos hídricos. Plano Nacional de Recursos Hídricos: Roteiro para consulta para elaboração de uma proposta. Brasília: MMA/SBF, 32p.

Brasil.(2008). Plano nacional de recursos hídricos: Programas de desenvolvimento da gestão integrada de recursos hídricos do Brasil, v. 1 / MMA, Secretaria de Recursos Hídricos. Brasília: MMA, 152p.

Brasil.(2010). Planos de Ação para a Prevenção e o Controle do Desmatamento Documento base: Contexto e análises. MMA, BRASIL, 2010.

Calheiros, D. F.; Castrilon S. K. I.; \& Bampi, A. C.(2018). Hidrelétricas nos rios formadores do pantanal: ameaças à conservação e às relações socioambientais e econômicas pantaneiras tradicionais. Revista IberoAmericana de Ciências Ambientais, 9(1), 119-139.

Calheiros, D. F.; \& Ferreira, C. J. A.(1997). Alterações limnológicas no rio Paraguai (decoada) e o fenômeno natural de mortandade de peixes no Pantanal Mato-grossense - MS. Corumbá. EMBRAPA-CPAP, 49 p.

Carvalho, J. (2018). Sema irá avaliar projeto de lei que implanta cota zero nos rios de Mato Grosso. SEMA MT. CUIABÁ. http://www.mt.gov.br/-/9437748sema-ira-avaliar-projeto-de-lei-que-implanta-cota-zero-nos-rios-de-mato-grosso

Catella, A. C.(2005). O monitoramento da pesca no Pantanal do Mato Grosso do Sul.

Conjuntura dos recursos hídricos no Brasil. (2013). Brasília, DF: Agência Nacional de Águas - ANA, 432 p. https://arquivos.ana.gov.br/institucional/spr/.

Da Cunha, C. N., Piedade, M. T. F., \& Junk, W. J. (Ed.).(2014). Classificação e delineamento das áreas úmidas brasileiras e de seus macrohabitats. EdUFMT.

Da Silva, C. J. \& Silva, J. A. F.(1992). Estratégias de sobrevivência de comunidades tradicionais no Pantanal Mato-grossense: relatório preliminar. Cuiabá: UFMT.

Da Silva, C.J.; Wantzen, K.M.; Nunes Da Cunha, C. E \& Machado, F.A. (2001). Biodiversity in the Pantanal wetland, Brazil. Biodiversity in wetlands: assessement, function and conservation, vol 2. Edited by B. Gopal, W.J. Junk and J.A. Davis, p. 1-29.

Da Silva, C. J. \& Girard, Pierre. (2004). New Challenges in the management of the Brazilian Pantanal and catchment área, Wetlands Ecology and Management, 12:553-561.

Da Silva, C. J.; Irigaray, C. T. J. H.; Faria, A. M. M.; \& Ribeiro, A. R.. (2015). Formação Socioambiental do Estado do Mato Grosso. In: Simonian, L. T. L.; Baptista, E. R. (Org.). Formação Socioambiental da Amazônia. Belém: NAEA, 379 - 392 p.

Dias, F. A.; Gomes, L. A.; \& Alkimin, J. K. (2011). Avaliação da qualidade ambiental urbana da bacia do ribeirão do Lipa através de indicadores, Cuiabá/MT. Sociedade \& Natureza, Uberlândia, 23 (1): 127-147.

Estrela, C. (2018). Metodologia Científica: Ciência, Ensino, Pesquisa. Editora Artes Médicas. 
Fiori A. P. \& Ciali A. (1999). Metodologia para obtenção do grau de erosão potencial mediante técnicas SIG e Sensoriamento Remoto. Boletim Paranaense de Geociências, Curitiba, n. 47.

Fiori, A.P.; Oka-Fiori, C.; Disperati, L.; Paranhos, A.C.; Kozciak, S. \& Ciali, A. (2001). O processo erosivo na Bacia do Alto Paraguai. Boletim Paranaense de Geociências, Curitiba, UFPR, (49), 63-78.

Fracalanza, A. P.; Campos V. N. O E \& Jacobi, P. R. (2009). Governança das Águas na Região Metropolitana de São Paulo (Brasil). O caso do Comitê de Bacia do Alto Tietê. In: Jacobi, P. R e Sinisgalli, P. A. (orgs.). Dimensões Político Institucionais da Governança das Águas na América Latina e Europa. São Paulo: Annablume.

Fracalanza, A. P.; \& Campos, V. N. O. (2010). Governança das águas no Brasil: Conflitos pela apropriação da água e a busca da integração como consenso. Ambiente \& Sociedade, 8(02), 365-382.

Galdino, S.; Vieira, L.M.; Padovani, C.R.; \& Soriano, B.M. (2004). Erosão Potencial Laminar Hídrica na Bacia do Alto Taquari. RBRH - Revista Brasileira de Recursos Hídricos, 9 (2), 125-13.

Gomes, C. S.(2008). Comitês de Bacias Hidrográficas de rios do médio São Francisco: possibilidades e desafios de gestão do uso de água. Lavras. UFLA.

Grizio, E.V. \& Souza Filho, E.E. (2010). As modificações do regime de descarga do rio Paraguai Superior. Revista Brasileira de Geomorfologia, São Paulo, $11(2), 25-33$.

Hamilton, S. K. (1998). Potential effects of a major navigation project (ParaguayParaná Hidrovia) on inundation in the Pantanal floodplains. Regulated rivers: Reseach e Management, p.1-11.

Hammer, Ø.; Harper, D.A.T.; Ryan, P. D.(2001). Paleontological statistics software: Package for education and data analysis. Palaeontologia Electronica, n. 4

Harris, M. B.; Arcangelo, C.; Pinto, E. C.T .; Camargo, G.; Ramos Neto, M .B.; \& Silva, S. M. (2005). Estimativas de perda da área natural da Bacia do Alto Paraguai e Pantanal Brasileiro. Relatório técnico não publicado. Conservação Internacional, Campo Grande, MS.

Instituto Ecoar Para Cidadania, Desafio das Águas- Agenda 21 do Pedaço.(1997). Fórum de Educação Ambiental /Encontro da Rede Brasileira de Educação Ambiental-RJ

Instituto Trata Brasil. (2018). Ranking do Saneamento. GO Associados - SP.

Jacobi, P. R. (2005). Comitês de bacias hidrográficas: o que está em jogo na gestão compartilhada e participativa. In: Dowbor, L; Tagnin. R. (orgs.). Administrando a água como se fosse importante. São Paulo: Editora Senac, p. 81-88.

Junk, W. J., Sousa Jr, P. T., Nunes Da Cunha, C., Piedade, M. T. F. E \& Candotti, E. (2011): Inundações catastróficas e deslizamento de barrancos em Minas Gerais e o novo Código florestal. Jornal da Ciência, SBPC.

Junk, W. J.; Bayley, P. B.; \& Sparks, R. E. (1989). The flood pulse conceptin river - floodplain. Can. Spec. Publ. Fih. Aquat. Sci., 106: p.110-127.

Leandro, G. R. S.; Andrade, L. N. P. S.; \& Bindandi, N. M.(2013). Processo de navegação e uso das margens no rio Paraguai no município de Cáceres - Mato Grosso. Revista GeoPantanal. UFMS/AGB. Grupo de Pesquisa Pantanal Vivo. Corumbá/MS. 8(14): p. 27-45.

Lima, J. B. \& Rondon Lima, E. B. N. (2009). Qualidade das águas das principais sub-bacias urbanas do município de Cuiabá. In: Figueiredo, D. M. e Salomão, F. X. T. Bacia do Rio Cuiabá: uma abordagem socioambiental. Cuiabá/MT. Entrelinhas. EdUFMT, p.140-145.

Lomba, R.M.; \& Lamoso, L.P.(2005). A expansão do setor terciário em função da atividade turística na cidade de bonito - Mato Grosso do Sul - Brasil. In: Anais do X Encontro de Geógrafos da América Latina.

Longo, J. M. \& Torrecilha, S. (Orgs). (2014). Roteiro Metodológico para Elaboração dos Planos de Manejo das Unidades de Conservação Estaduais de Mato Grosso do Sul. Imasul.

López-Ramírez, M. E. (2016). A gestão complexa da água. In:Participação e controle social em saneamento básico - Conceitos, potencialidades e limites. Orgs.: Léo Heller, Marluce Martins Aguiar, Sonaly Cristina Rezende. - Belo Horizonte: Editora UFMG.

Ludke, M. \& Andre, M. E . D. A. (2013). Pesquisas em educação: uma abordagem qualitativa. São Paulo: E.P.U.

Magalhães Filho, F. J. C.; \& Paulo, P. L.(2017). Abastecimento de água, esgotamento doméstico e aspectos de saúde em comunidades Quilombolas no Estado de Mato Grosso do Sul. Interações, Campo Grande, MS, 18(2), 103-116.

Marchetto, M.; et. al. (2018). Avanços e desafios da Politica de recursos hídricos quanto aos instrumentos de gestão. In: Bacia do Rio Cuiabá: uma abordagem socioambiental. Figueredo, D.M.; Dores,E.F.G.C e De Lima, Z.M (orgs.). Cuiabá-MT: EdUFMT. 716 p.

Mato Grosso Do Sul.(2002). Lei n 2.406, de 29 de janeiro de 2002 Publicada no DO-MS em 30/01/2002. Institui a Política Estadual dos Recursos Hídricos, cria o Sistema Estadual de Gerenciamento dos Recursos Hídricos e dá outras providências.

Mato Grosso .(1997). Lei estadual № 6.945 de 05 de Novembro De 1997. Dispões sobre a Política Estadual de Recursos Hídricos. Institui o Sistema Estadual de Recursos Hídricos e dá outras providências.

Mato Grosso. (2017). Substitutivo integral ao Projeto de Lei 460/2017, que modifica e acrescenta dispositivos à Lei 9.096/2009. A Assembleia Legislativa Do Estado De Mato Grosso, tendo em vista o que dispõe o artigo 42 da Constituição Estadual, aprova e o Governador do Estado sanciona a seguinte Lei. https://www.al.mt.gov.br/storage/webdisco/cp/20180228174352124100.pdf 
Mendes, N. F.(1992). Efemérides Cacerenses. 2. ed. Brasília: Centro Gráfico do Senado Federal.

Mesquita, L. F. G. (2018). Os comitês de bacias hidrográficas e o gerenciamento integrado na Política Nacional de Recursos Hídricos. Desenvolv. Meio Ambiente, 45, 56-80.

Migliácio, M. C.(2001). IPHAN Denuncia Riscos ao Patrimônio Arqueológico pelo Projeto de porto de Morrinhos. In: VIANA, G. A polemica sobre a Hidrovia Paraguai Paraná e o Porto de Morrinhos. 3 ed. Coleção Eco-Cidadania. Mato Grosso: Assembléia Legislativa de Estado de Mato Grosso, p. 113 119.

Milani, C. R .S. (2008). O princípio da participação social na gestão de políticas públicas locais: uma análise de experiências latino-americanas e europeias. Rio de Janeiro, 42(3), 551-79.

Moreira, A. C. (2018). Hidrovia do Paraguai. DNIT. BRASIL. http://www.dnit.gov.br/modais-2/aquaviario/hidrovia-do-paraguai.

Moretti, E. C.; Marinho, V. L. F. (2016).A gestão de recursos hídricos no Brasil e os comitês de bacias hidrográficas - a experiência do cbh-Miranda (MS). Revista da Associação Nacional de Pós-graduação e Pesquisa em Geografia (Anpege), 12(17), 123-140.

Oliveira, C. F. (2005). A gestão dos serviços de saneamento básico no brasil. Scripta Nova, 9(194), tomo 73.

PAE. (2004). Implementação de Práticas de Gerenciamento Integrado de Bacia Hidrográfica para o Pantanal e Bacia do Alto Paraguai ANA/GEF/PNUMA/OEA: Programa de Ações Estratégicas para o Gerenciamento Integrado do Pantanal e Bacia do Alto Paraguai: Relatório Final/Agência Nacional de Águas - ANA ... [et al.]. - Brasília: TDA Desenho \& Arte Ltda.

Paranhos Filho, A. C.; Fiori, A. P.; Disperati, L.; Lucchesi, C.; Ciali, A.; \& Lastoria, G.(2003). Avaliação multitemporal das perdas dos solos na bacia do rio Taquarizinho através de SIG. Boletim Paranaense de Geociências, Curitiba, 52, 49-59.

Paschoal, F. (2019). Lama se espalha por rios cristalinos de Bonito e ameaça paraíso. Campo Grande. SOS PANTANAL. http://www.sospantanal.org.br/arquivos/blog/assoreamento-rios-bonito-ms.

Pawlowski, C. S.; Andersen, H. B.; Troelsen, J. \& Schipperijn, J. (2016). Children's physical activity behavior during school recess: A pilot study using GPS, accelerometer, participant observation, and goalong interview. Plos One.

Pearce, F.; Madgwick, J. (2020). Water Lands: A vision for the world's wetlands and their people. London, Harper Collins Publishers.4380 p.

Pereira, D. (Coord.) (2003). Governabilidade dos Recursos Hídricos no Brasil: a implementação dos Instrumentos de Gestão na Bacia do Rio Paraíba do Sul. Brasília: Agência Nacional de Águas.

Pignati W A, \& Machado J M H. (2011). O agronegócio e seus impactos na saúde dos trabalhadores e da população do Estado de Mato Grosso. In: Gomez CM, Machado JHM, Pena PG, organizadores. Saúde do trabalhador na sociedade brasileira contemporânea. Rio de Janeiro: Fiocruz; p. $245-272$.

Ponce, V. M. (1995). Impacto hidrológico e ambiental da hidrovia Paraná-Paraguai no pantanal matogrossense-Um Estudo de Referência. San Diego State University. San Diego, Califórnia.

Raffestin, C. (1993). Por uma geografia do poder. São Paulo: Ática.

Real, R.; \& Vargas, J. M. (1996).The probabilistic basis of Jaccard's index of similarity. Systematic biology, 45(3), $380-385$.

Risso, A.; Bordas, M. P.; \& Borges, A. L.(1997). Produção de sedimentos. In: BRASIL. Ministério do Meio Ambiente, dos Recursos Hídricos e da Amazônia Legal. Pla-no de Conservação da Bacia do Alto Paraguai (Pantanal) - PCBAP. Hidrossedimentologia do Alto Paraguai. Brasília, 2 , $271-307$.

Rondon Lima, E. B. N.; et al.(2018). Panorama do Saneamento Básico no Consórcio Intermunicipal do Vale do rio Cuiabá. In: Bacia do Rio Cuiabá: uma abordagem socioambiental. Figueredo, D.M.; Dores,E.F.G.C e De Lima, Z.M (orgs.). 1ª edição. Cuiabá-MT: EdUFMT, 716 p.

Rossi, R. A.; \& Santos, E. (2004). Conflito e regulação das águas no brasil - a experiência do salitre. Caderno CRH Salvador, v.31, n.82, p. 151 - 167, 2018. Salvati, S.S. (org.). Turismo Responsável-Manual para Políticas Públicas. Brasília, DF: WWF Brasil.

Sanesul/ACOM-Bonito(2019): universalização da água e esgotamento sanitário. Empresa de Saneamento de Mato Grosso do Sul - SANESUL. Campo Grande. http://www.sanesul.ms.gov.br/noticias/bonito-universalizacao-da-agua-e-esgotamento-sanitario

Santos, E. L. F.; Medeiros, Q. H.; \& Da Silva, C. J. (2013). Educação ambiental e diálogo de saberes em região de nascentes do Pantanal: Reserva do Cabaçal, Mato Grosso, Brasil. Ciência educ. (Bauru) 19(4).

Santos, I. A.; \& Saito, C. H. (2006). A mitificação da participação social na política nacional de recursos hídricos - gênese, motivação e inclusão social. Geosul, 21(42).

Santos, R. de S. (2016). A microrregião geográfica de Rondonópolis-MT e sua polarização na economia regional. Revista nera, n. 33.

Santos, S. A. Crispim, S. M. A.; Filho, J. A. C.; \& Cardoso, E. L.(2004). Princípios de agroecologia no manejo das pastagens nativas do Pantanal - Corumbá: Embrapa Pantanal, 35p.

Santos, S. M.; Souza, M. M. P.; Bircol, G. A. C.; \& Ueno, H. M.(2020). Planos de Bacia e seus desafios: o caso da Bacia Hidrográfica do Alto Tietê - SP. Ambiente \& Sociedade São Paulo. Vol. 23.

Seplan-MT - Secretaria de Estado de planejamento e orçamento de Mato Grosso. (2002). Diagnóstico sócio-econômico-ecológico do Estado de Mato Grosso. Cuiabá. 
Research, Society and Development, v. 10, n. 10, e507101018137, 2021

(CC BY 4.0) | ISSN 2525-3409 | DOI: http://dx.doi.org/10.33448/rsd-v10i10.18137

Silva, C \& Silva J. (1992). Estratégias de sobrevivência de comunidades tradicionais no Pantanal Matogrossense. São Paulo, NUPAUB-USP.

Silva, H.P.; \& Rocha, N.M.; Ikeda-Castrillon,S.K. (2004). O impacto da proposta de implementação da Hidrovia Paraguai-Paraná, na visão de diversos setores da sociedade em Cáceres, MT. In: IV Simposio sobre recursos naturais e socio-economicos do pantanal. CORUMBÁ/MS - 23 A 26 NOV.

Silva, N. B. da, Lopes, J. O., Brito, J. D. de M., Takiyama, L. R., Montagner, A. E. A. D., \& Oliveira, E. D. C. de. (2018). Diagnóstico da qualidade da água em áreas utilizadas pela bubalinocultura no Baixo Araguari, Amapá, Brasil. Biota Amazônica, 8, 22-28

Sinclair, S. \& Rockwell, G. (2012). Teaching computer assisted text analysis. Digital Humanities Pedagogy: Practices, Principles and Politics. Brett D. Hirch, ed. Open Book Publishers.

Sneath, P. H. A.; \& Sokal, R. R. (1973). Numerical taxonomy. The principles and practice of numerical classification. San Francisco, 573 pp.

Souza Filho, E. E. (2013). As barragens na bacia do rio Paraguai e a possível influência sobre a descarga fluvial e o transporte de sedimentos. Bol. geogr., Maringá, 31(1), 117-133.

Trentin, F.; \&Gruber D. S.(2006). Políticas públicas de turismo e indicadores de sustentabilidade ambiental: um estudo sobre Bonito - MS Turismo. Universidade do Vale do Itajaí Camboriú, Brasil. Visão e Ação, 8(1), . 61-74.

Wantzen, K. M., da Cunha, C. N., Junk, W. J., Girard, P., Rossetto, O. C., Penha, J. M., Couto, E. G., Becker, M., Priante, G., Tomas, W. M., Santos, S. A., Marta, J., Domingos, I., Sonoda, F., Curvo, M., \& Callil, C. (2008). Towards a sustainable manegement concept for ecosystem services of the Pantanal Wetland.Ecohydrology \& Hydrobiology, 8, 115-138.

WWF-Brasil. (2001).A Conservação da Biodiversidade no Pantanal: Uma Pesquisa de Opinião. Universidade Católica Dom Bosco (UCDB) e WWF: Brasília. 